\title{
The Borrowed-Reserves Operating Procedure: Theory and Evidence
}

\author{
Daniel L. Thornton
}

I

N LATE 1982, the Federal Reserve switched from a nonborrowed-resenves to a borrowed-reserves operating procedure.' Analysts generally believe that the adoption of this procedure, which involves the use of a "borrowings assumption" specified by the Federal Open Market Committee (FOMC), represents a policy reversal toward the setting of the federal funds rate and away from direct money stock control.

This paper discusses the merits of the borrowedreserves operating procedure as a method for money stock or interest rate control, analyzes the relationships between the borrowings assumption, the federal funds rate and the discount rate, and provides some evidence on how the new procedure has been used since late 1982 .

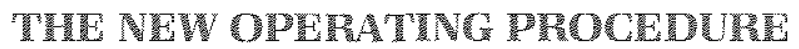

The comerstone of the borrowed-resenves operat ing procedure is the borrowings function, which reflects the basic economic factors that induce depository institutions to borrow from the Federal Reserve. It is usually argued that the level of borrowings (Borr) from the Federal Reserve is influenced primarity by the spread between the federal funds rate (FFR) and the Federal Reserve's discount rate (DR). Accordingly, the borrowings function is

(1) $\operatorname{Borr}_{1}=\mathrm{b}_{0}+\mathrm{b}_{1}\left(\mathrm{FFR}_{4}-\mathrm{DR}_{1}\right)+\mathrm{v}_{0}$

where $b_{0}$ and $b_{1}$ are constants $\left(b_{4}>0\right.$. The random error term, $v_{t}$, captures the effect of all other factors that determine depository institutions' borrowings. It can be thought to represent "transitory" shocks to the borrowings function, while changes in $b_{n}$ represent

Daniel $L$. Thornton is a research officer at the Federal Reserve Bank of St. Louis. Rosemarie V. Mueller provided research assistance.

For a discussion of this change, see Roley (1986), Wallich (1984) Federal Reserve Bank of New York (1986) and Gilbert (1985). "permanent" shifts in the function. This distinction will be useful later.

The equilibrium FFR, given DR, is determined by the demand for and the supply of total reserves. The supply of total reserves is composed of nonborrowed reserves (NBR) and reserves supplied through the discount window. The demand for total reserves is composed of the demand for required plus excess reserves. Theory suggests that the demand for reserves is inversely related to the federal funds rate. Equating the demand for and the supply of total reserves results in an equilibrium equation for the federal finds rate of the general form

(2) $\mathrm{FFR}_{1}=\mu_{0}-\mu_{1} \mathrm{NBR}_{1} \quad \mu_{0 r} \mu_{1}>0$.

This equation shows all possible combinations of nonborrowed reserves and federal funds rates for which the supply of and the demand for total reserves are equal. Equation 1, presented in figure tb, and equation 2, presented in figure ta, can be used to illustrate how the borrowings procedure operates and to show similarities and differences between a borrowings operating procedure and a federal funds rate targeting procedure. Suppose the bortowings assumption is set at Borr*, shown in figure $1 \mathrm{~b}$. The borrowings assumption represents the amount of reserves that the Fed wishes to induce depository institutions to borrow from the discount window. This implies $\mathrm{PRR}$ must equal FFR*. Given the demand and supply functions, the Fed can hit its borrowings target by supplying nonborrowed reserves equal to $\mathrm{NBR}^{*}$. This establishes an equilibrium FFR at FFR* consistent with the borrowings objective.

While figure 1 clarifies the relationship between the borrowings objective, the funds rate and nonborrowed reserves, it may be unfamiliar to many readers. Consequently, from this point on, the analysis will be illustrated in terms of the more familiar figure 2. (See appendix $A$ for a discussion in terms of figure 1 and the details conceming the variances of the federal funds rate and borrowings stated in the text.) In figure 


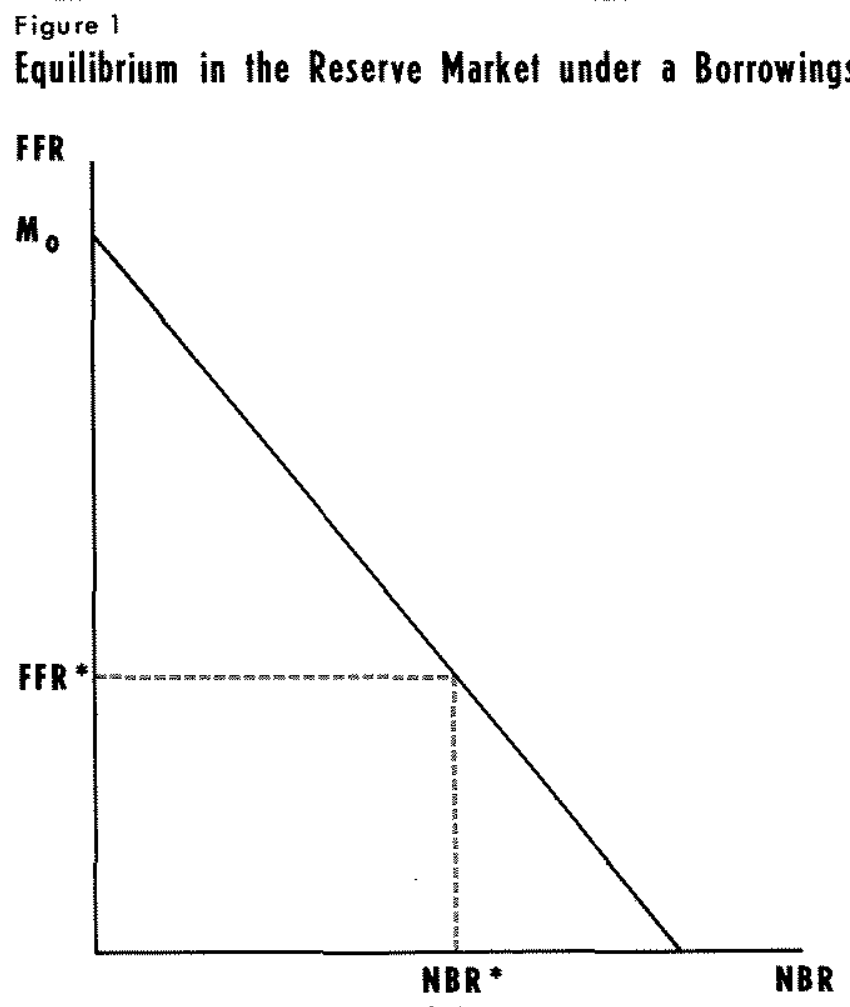

(a)

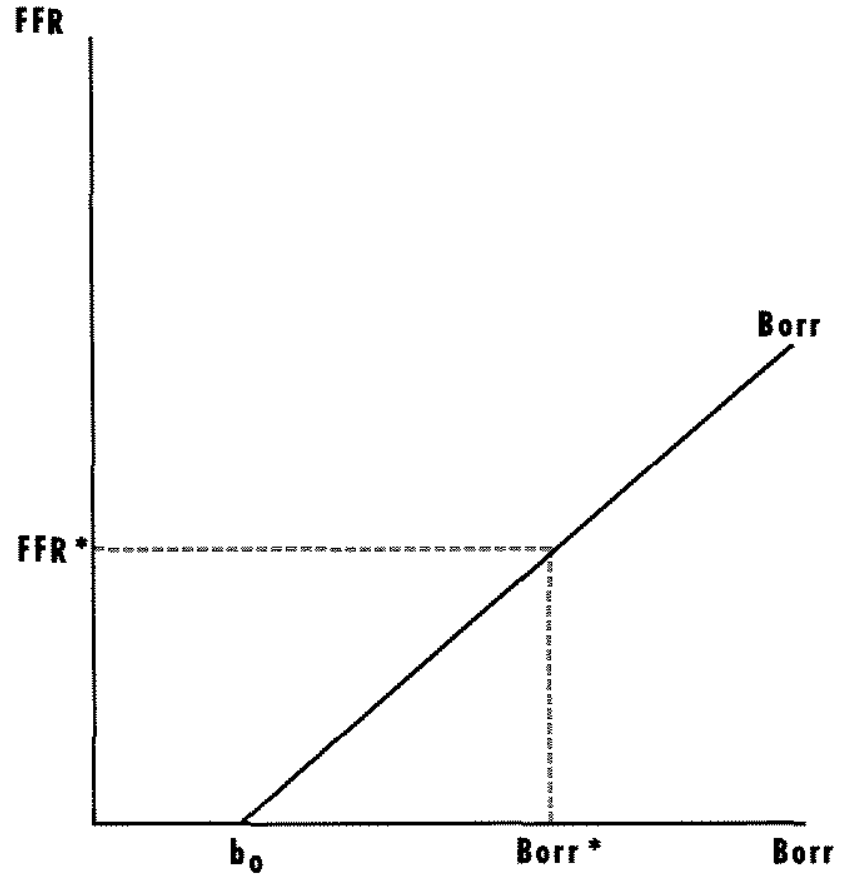

(b)
2 , the supply of total reserves is obtained by adding borrowed reserves (from equation 1) to the desired level of nonborrowed reserves, $\mathrm{NBR}^{*}$, on the assumption that $b_{0}>0$ (see the shaded insert). The equilibrium federal funds rate, $\mathrm{FFR}^{*}$, is determined by the intersection of the supply and demand curves in figure 2. As before, the target level of borrowings is achieved by providing the appropriate amount of nonborrowed reserves.

\section{How the Fed Should Respond to}

\section{Shock}

\section{procedure}

To understand properly the efficacy of the borrowings procedure as a method of money stock or interest rate control, it is important to see how the Fed reacts to shocks when using it. First, consider its response to an increase in the demand for total reserves, illustrated in figure $3 \mathrm{a}$. Other things constant, an increase in the demand for total reserves causes the equilibrium funds rate to rise from FFR to FFR' $^{* \prime}$ and borrowings to rise from the desired level $\left(\mathrm{TR}^{*}-\mathrm{NBR}^{*}\right.$ ) to $\left(\mathrm{TR}^{* \prime}-\mathrm{NBR}^{*}\right)$. To bring borrowings back to its desired level, the supply of nonborrowed reserves must be increased via an open market purchase of government securities. This reduces the federal funds rate and

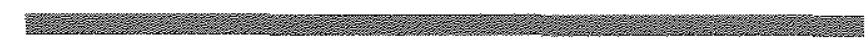

Figure 2

Equilibrium in the Reserve Market under a Borrowings Procedure

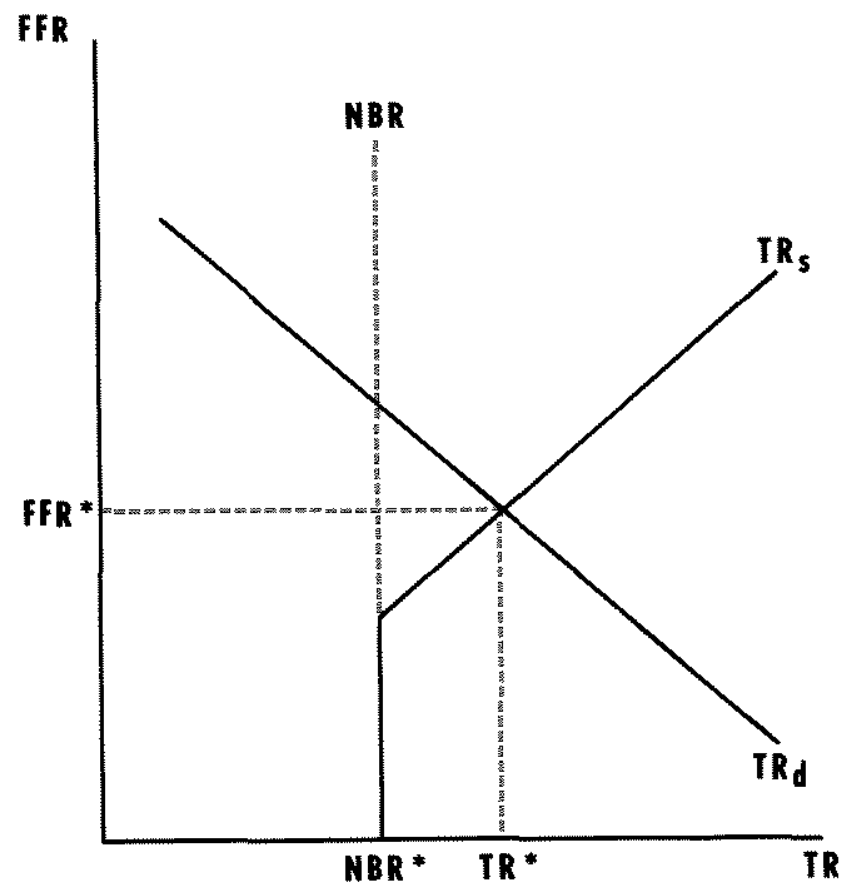




\section{The Borrowings Function: A Supply or Demand Curve?}

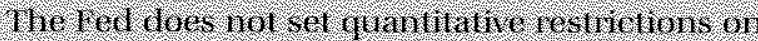

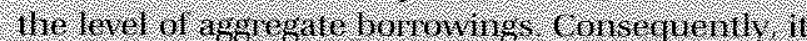

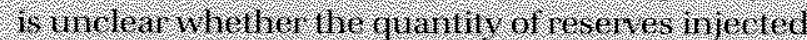

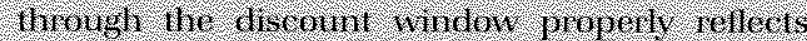

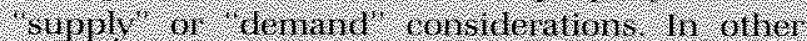

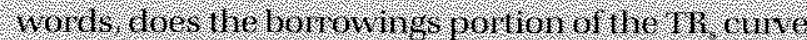

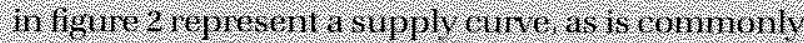

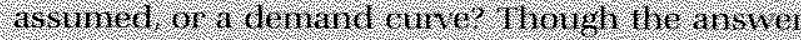

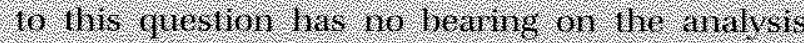

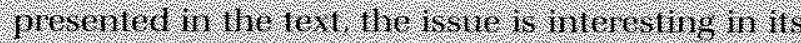

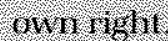

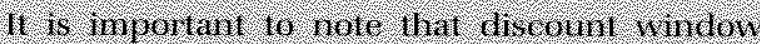

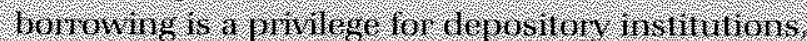

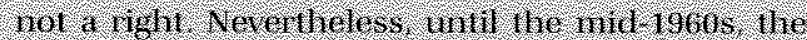

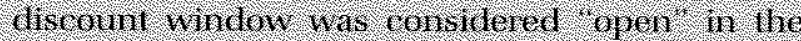

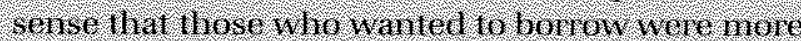

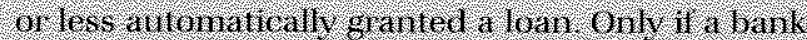

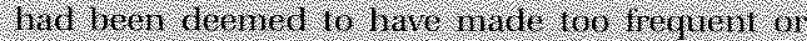

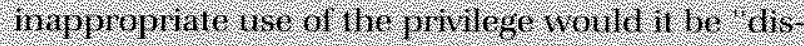

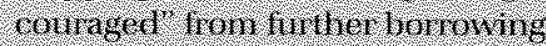

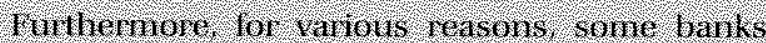

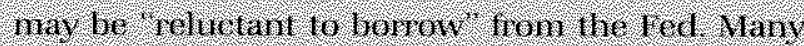

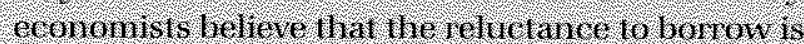

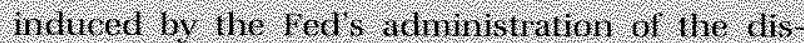

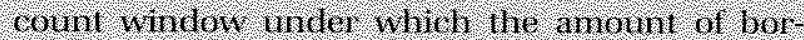

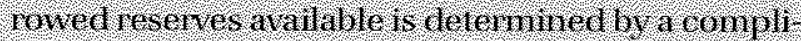
cated system of price all hon price ralioning

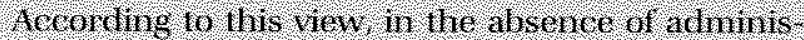

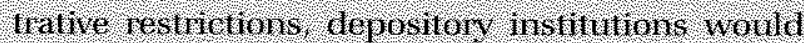

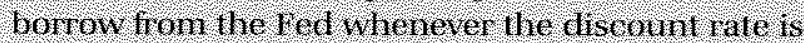
below the rederal huds rate, alld oblan fonds in the tederal funds narkel whenever ho tedoral

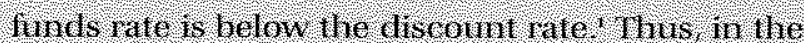

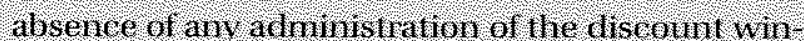
dow, the discount rate should establist an eltertive rening for the federal hinds tate.

If wive, whe supply of resentes showld he perfoetly interest-elaslie at or below he cument discount

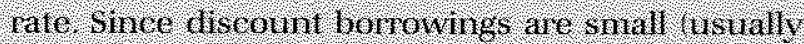

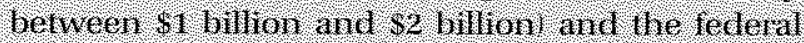
fullds rale is generally above the discount rate. it is arten assumed hat here is non price rationmg at

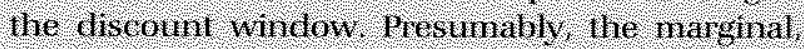
hon-pecumary lationing bost is hot amount by

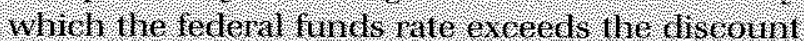
rate. This sponead is lhe nar ginal jochinm depost

See Geodiriend (1083)

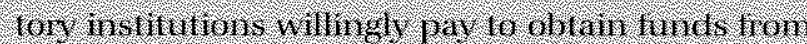

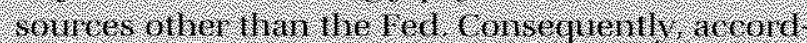

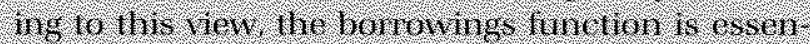

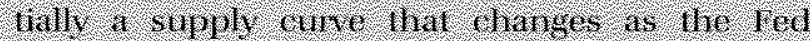

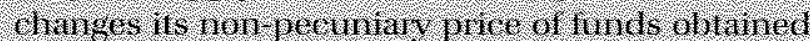
at he disconth whatho

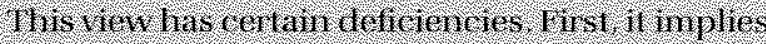

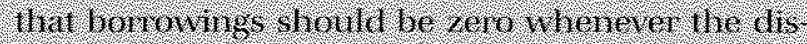

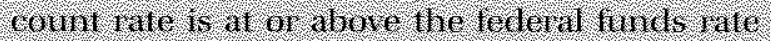

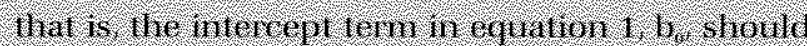

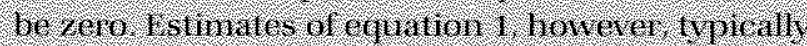

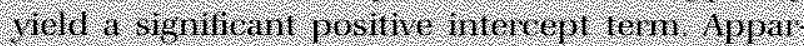

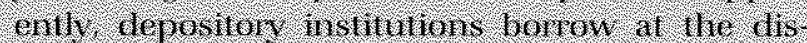

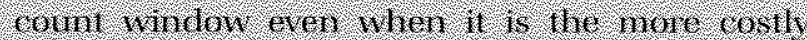

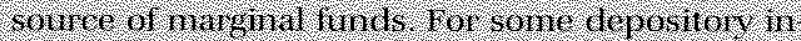

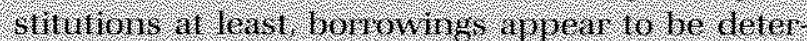

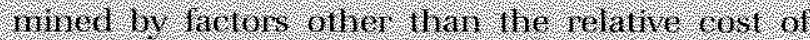

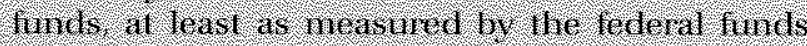

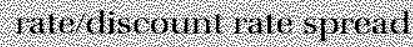

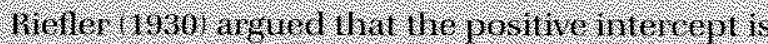

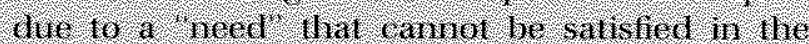

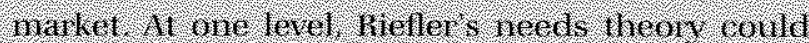

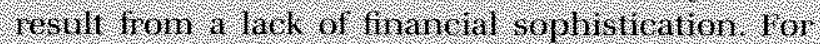

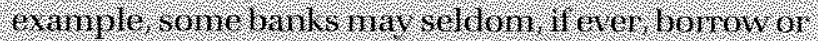

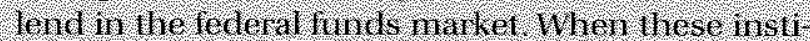

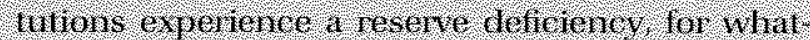

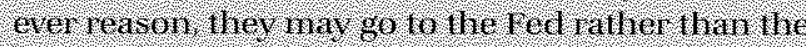

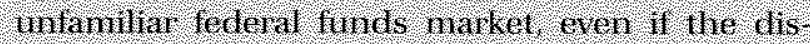
count rate is alvove ine rederal funds rate. Wiewed

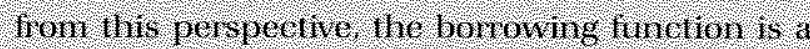

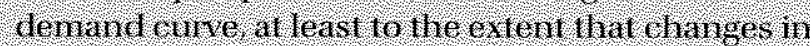

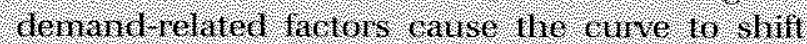

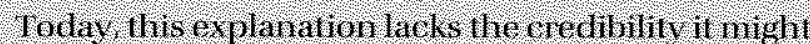

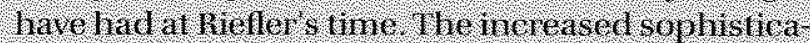
tor of depository instititions ard the wades jead use of contespondent barking have weakened the vallity or livis ars ment.

A different explahation for the posilive constan

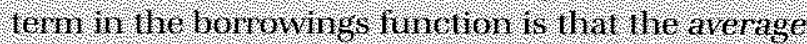
fradert tumds rarc does not rephesent the relevant

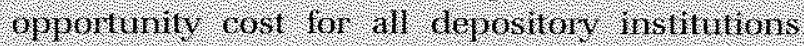

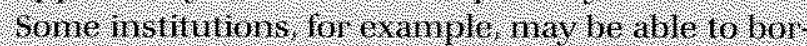

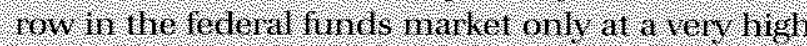

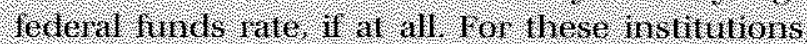

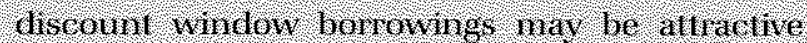

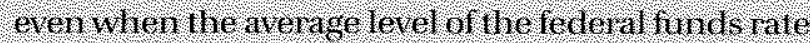
is well below he discount late, ha this case loo

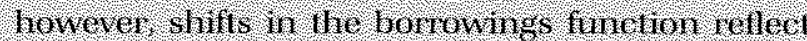

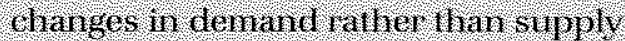


Figure 3

\section{The Effect of an Increase in the Demand for Total Reserves under a Borrowings Procedure}

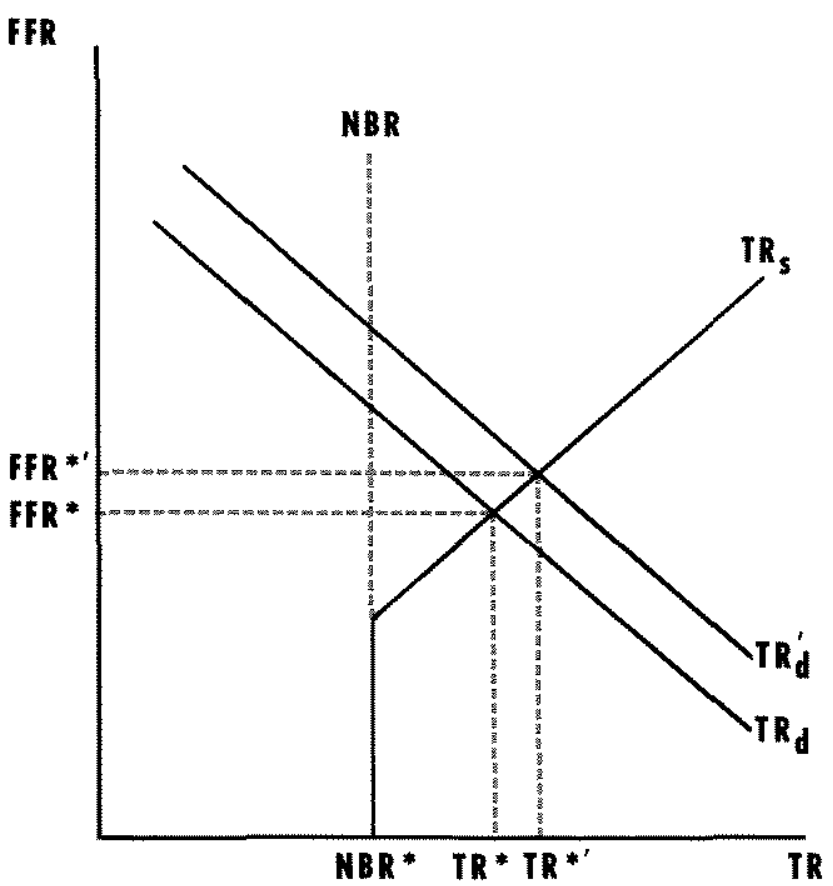

(a)
FFR

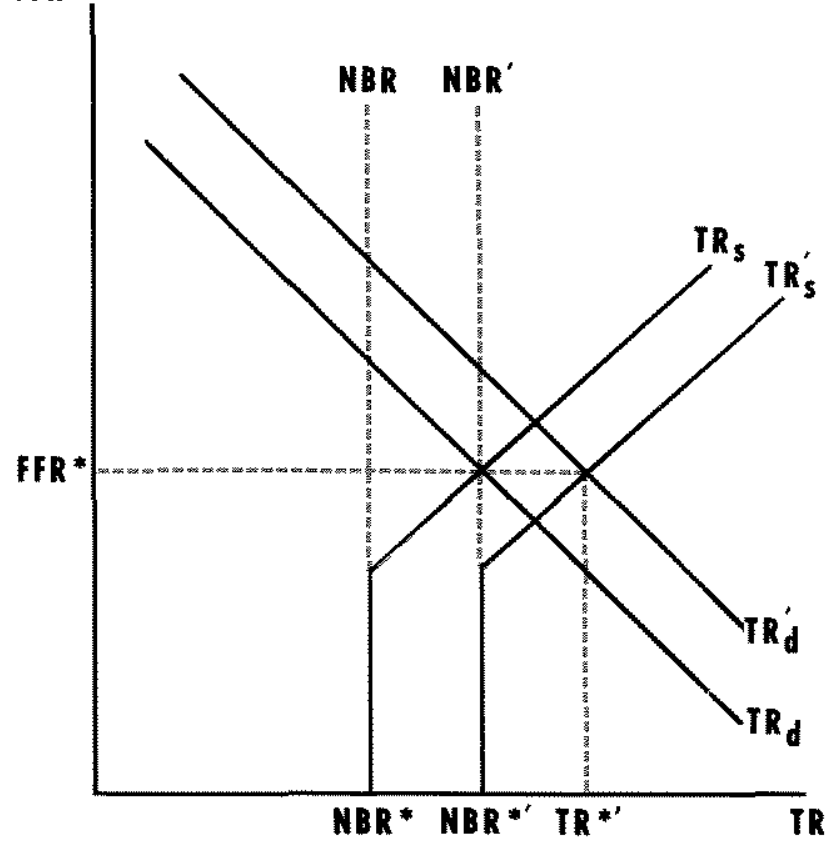

(b) brings borrowings back to Borr*; that is, $\left(\mathrm{TR}^{*}-\mathrm{NBR}^{*}\right.$ ) equals $\left(T^{* \prime}{ }^{*}-N^{*} R^{* \prime}\right.$, as shown in figure $3 b$. Conse* quently, neither borrowings nor the federal funds rate is changed; instead, the demand for total reserves is satisfied by an increase in NBR.

Alternatively, the borrowings function could shift to the fight, illustrated by the rightward shift in the $\mathrm{TR}_{\text {s }}$ function in figure 4a. Other things the same, borrowings will increase and the equilibrium federal funds rate will decline from $\mathrm{FFR}^{*}$ to $\mathrm{FFR}^{* \prime}$. If the borrowings assumption is maintained at $B \mathrm{Br}^{*}{ }^{*}$, the supply of nonbofrowed reserves must be increased. This will put further downward pressure on the fedenal funds rate until it reaches FFR $^{* \prime \prime}$ (see figure 4 b), inducing borrowings back to Borr*. In this instance, borrowings are unchanged and the funds rate falls.

\section{The Borrowings Procedure: An Ineffecture Tool for Money Stock Control}

The above analysis suggests that strict adherence to the borrowings procedure will not provide effective money stock control. If borrowings are kept at the assumed level, changes in the demand for money and, hence, reserves will be accommodated by compensatory changes in the supply of reserves. This is illus- trated by the usual money supply/money demand paradigm shown in figure 5a. Here, the money supply is positively related to the FFR and is drawn holding the discount rate and the level of nonborrowed re" serves unchanged. ${ }^{2}$ As usual, the demand for money is negatively related to the interest rate. If the borrowings procedure is used to control the money stock, a money target, $\mathrm{M}^{*}$, must be established, Given the demand for money and the discount rate, this requires achieving a specific interest rate, FFR* Given the borrowings function, this implies a target level of borrowings (Borr*) and target setting for nonborrowed re* serves $\left(\mathrm{NBR}^{*}\right)$.

The supply of money is positively sloped on the assumption that borrowings are positively related to the funds rate and that the demand for other reservable components of the monetary base is negatively related to the funds rate. See Thornton (1982b) for a model that incorporates these assumptions.

The federal funds rate is not used commonly as the representative interest rate for money demand. But it is used commonly in money supply models as well as those that incorporate both money supply and money demand functions. This may not be desirable, especially if the relationship between the funds rate and the true representative rate in the money demand equation is either highly variable or affected by changes in policy or policy-related variables. it is adequate, however, if there is a fixed proportionate reationship between these rates. 
Figure 4

The Effect of an Increase in the Borrowings Function under a Borrowings Procedure

FFR

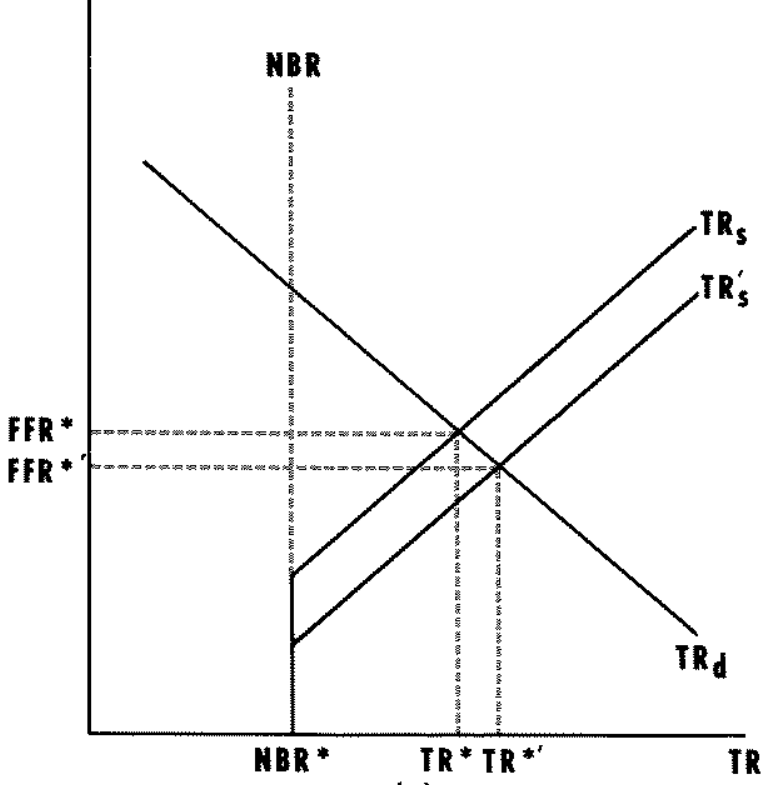

(a)

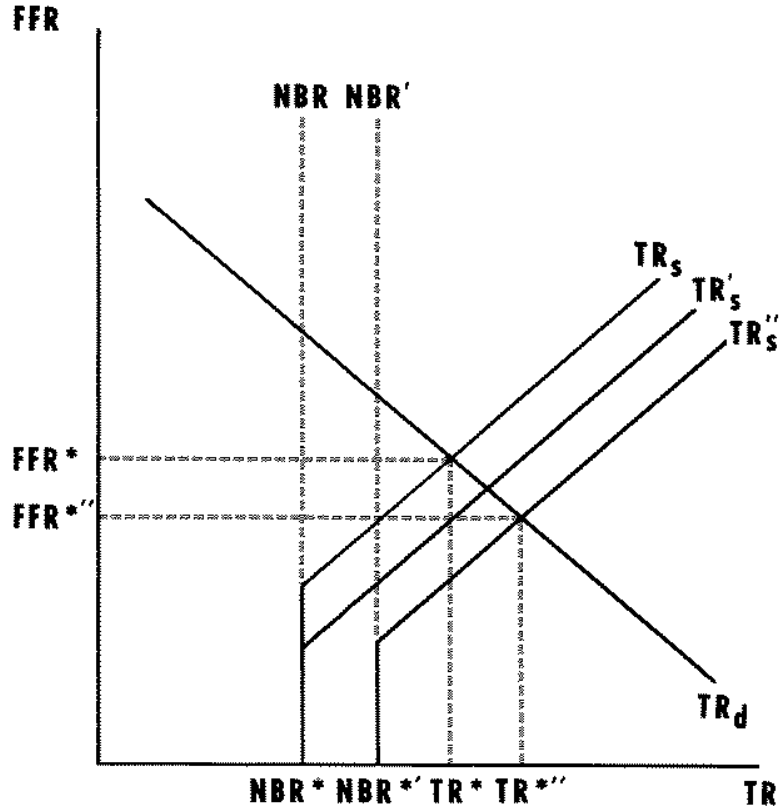

(b)
Suppose the demand for money increases from $M_{d}$ to $\mathrm{M}_{\mathrm{fl}}^{\prime}$ " Other things the same, the resulting rise in the funds rate would increase borrowings. In order to reduce borrowings back to Borr*, the supply of nonborrowed reserves must increase from $\mathrm{NBR}^{*}$ to $\mathrm{NBR}^{* *}$, shifting the money supply schedule to the right as shown in figure 5a. Because borrowings depend only on the level of the federal funds rate (given the discount rate and assuming the function is otherwise stablel, the desired level of borrowings can be achieved by supplying the requisite quantity of nonborrowed reserves. Hence, all shifts in the demand for money are accommodated by corresponding shifts in the money supply if Borr* remains unchanged. In this case, no difference between money stock control under a borrowings procedure and a federal funds rate targeting procedure exists.

${ }^{3}$ Total reserves demand is composed of the demand for requited and excess reserves. The demand for required reserves can be thought of as a derived demand, derived from the demand for money via the relationship between checkable deposits and required reserves. Because the demand for money generally is estimated to be interest-inelastic, the demand for required reserves should also be interestinelastic. Of course, during the lagged reserve accounting (LRR) period prior to February 1984 , the demand tor required reserves should be perfectly interest-inelastic. (See Thornton (1983) for a discussion of the differences between lagged and contemporaneous reserve accounting.) The demand for excess reserves usually is found to be relatively interest-insensitive as well.
Now, suppose the borrowings function temporarily increases, that is, $v_{1}>0$. This produces a temporary rightward shift in the money supply from $\mathrm{M}_{s}$ to $\mathrm{M}^{r}$, as illustrated in figure 5b. Other things the same, the federal funds rate falls and borrowings increase. To bring borrowings back to Borr*, nonborrowed reserves must be increased, shifting the money supply schedule still further to the right from $\mathrm{M}^{\prime}{ }_{\mathrm{s}}$ to $\mathrm{M}^{\prime \prime}$. As a result the money stock is further away from its targeted level, $\mathrm{M}^{*}$. Strictly enforced, the borrowings operating procedure yields less short-term control over the money stock than a straight forward federal funds rate targeting procedure as long as the borrowings function is subject to some variability and the Fed makes no allowance for the shift.

\section{The Borrowings Pronedure as a Federal Funds Tate Target}

The borrowings procedure produces results that are identical to those using a federal funds rate targeting procedure if all shocks emanate from the demands for money or reserves. The two procedures yield dif-

\footnotetext{
The assumption here is that the discount window is assumed "open," given a set of unchanged administrative constraints.

${ }^{5}$ This point has also been made by VanHoose (1988).
} 
Figure 5

\section{The Eftect of an Increase in the Demand for Money and the Borrowings Function on the Money Supply under a Borrowings Procedure}

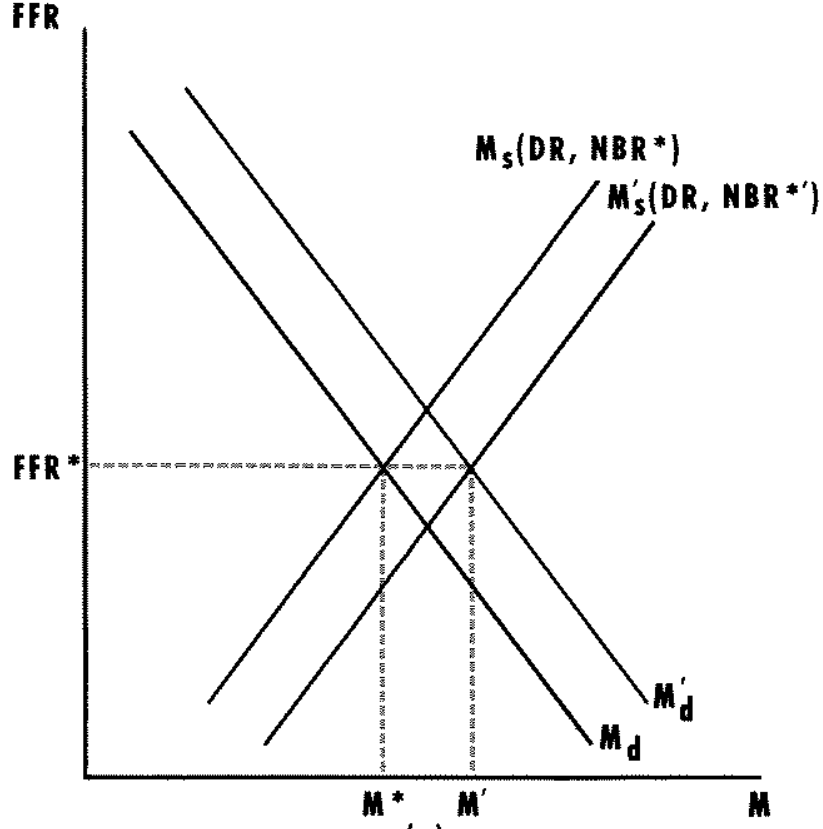

(a)

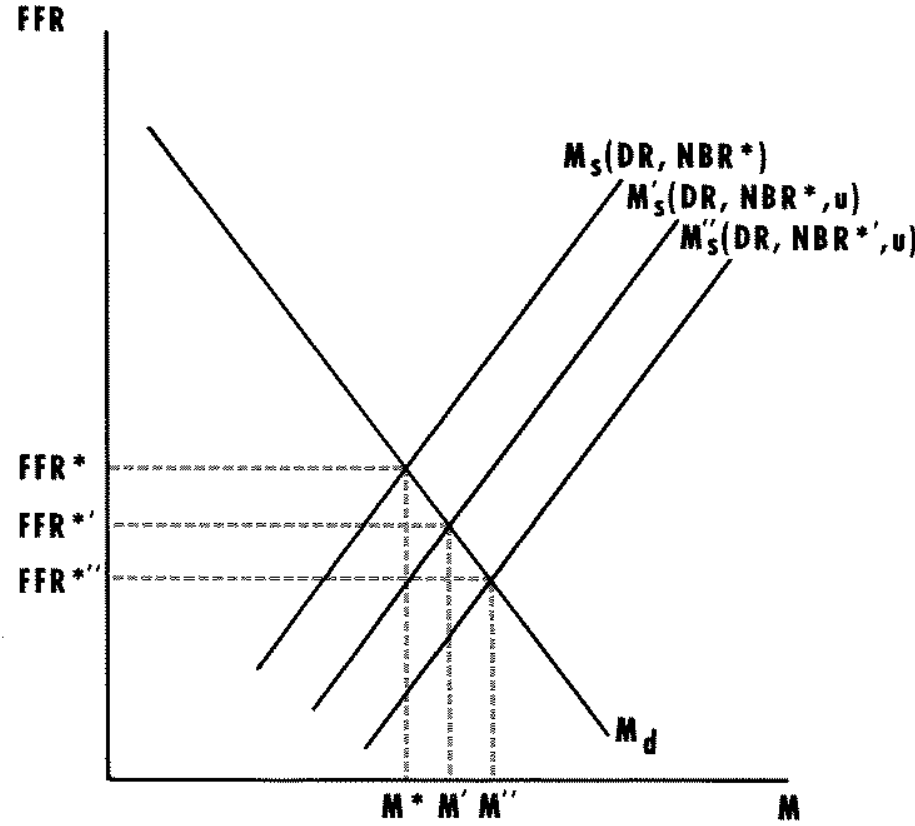

(b) ferent results, however, when there are shifts in the borrowings function. The borrowings procedure exacerbates the effect of short-run fluctuations in the borrowings function on the funds wate. If any part of such shifts is offset by changes in NBR, the borrowings procedure will produce greater variability in the federal funds rate and less variability in borrowings than a direct funds rate targeting procedure. Indeed, under a borrowings procedure, the variability of borrowings will be less than the variability of the funds rate under failly general conditions. ${ }^{7}$ Nevertheless, if the borrowings function is stable (in the sense that all fluctuations are transitoryl, fluctuations in the federal funds

'Roley (1986) argues that, while the Fed moves quickly to offset changes in the ctemand for total reserves, it does not do so for changes in the borrowings function. Thus, he argues that the federal funds rate will vary more in the short run under a borrowed-reserves procedure than under a lederal-funds-rate targeting procedure. Roley's assertion implies the Fed can distinguish between shifts in these two functions.

The relative variability of borrowings will be less if the stope of the total reserves supply function in figure 2 is flatter than that of the demand for total reserves - a condition that is likely to hold - or if the Fed is reasonably successful in offsetting the effect of shitts in the borrowings function. See appendix $A$ for delails. rate will net out over time $\left[\mathrm{E}\left(\mathrm{v}_{\mathrm{z}}\right]=0\right]$; therefore, the botrowings operating procedure can be used to achieve a federal funds rate target over a somewhat longer-term horizon."

Of course, the borrowings function also could exhibit permanent shifts associated with changes in $b_{f 1}$ in equation 1. In this instance, the assumed level of borrowings would be achieved only with a substantial change in the federal funds ate." For example, if borrowings are maintained at a predetermined level despite a permanent decrease in the borrowings function, nonborrowed reserves must be reduced unt the federal funds rate rises enough to return borrowings to their former level. On the other hand, if the federal funds rate is kept at its former level, the borrowings assumption must be lowered.

${ }^{5}$ The two procedures are equivalent if the shocks to both the demand for total reserves and borrowings exhibit no persistence and if no attempt is made to offset such temporary shocks. See appendix $A$ for details.

Wallich (1984), p. 26, notes that the borrowings function is unstable. Therefore, he contends the borrowings procedure cannot be rem garded as a form of "rate-pegging, " because the ". . chosen level of borrowing is consisient with any range of values of the funds rate." 
In summary, the borrowings operating procedure is a useful surrogate for a short-run federal funds rate targeting procedure only if all changes in aggregate borewings are produced by shifts in the demand for total reserves. It is a useful surmogate for a longer run federal funds rate targeting procedure only if the borrowings function is stable, that is, subject only to temporary, random shifts. It is unsuited for a federal funds rate target whenevet there are permanent shifts in the borrowings function, unless the borrowings assumption is changed sufficiently.

\section{The Poldey Inplications of echange in the Borrowings Assumpton}

Usually, monetary aggregates or interest rates are chosen as intermediate policy targets. Why is the borrowings procedure used when the money stock or the funds rate could be more directly controlled by other procedures? What are the policy implications of a change in the borrowings assumption? Without precise information about the intermediate policy target, it is difficult to answer these questions definitively; nevertheless, some generalizations can be made.

If the borrowings function is stable, an increase in the borrowings assumption can be interpreted as a move toward restraint in that it reduces the supply of reserves relative to demand. Conversely, a decrease is a movement toward ease. If the borrowings function is unstable, in the sense that permanent shifts occur, however, changes in the borrowings assumption may reflect the Fed's awareness of these shifts and its desire to mitigate their effect on the funds rate. A failure to change the borrowings assumption, on the other hand, could be interpreted as a movement toward ease or restraint, depending on the direction of the shift of the borrowings function.

\section{The Relationship Between Changes in the Borrowings Assumption and Changes in the Discount Rate}

Changes in the borrowings assumption and the discount rate can be viewed as substitutes. Because it depends on the discount rate, the $T_{\text {s }}$ curve shifts with a change in the discount rate. For example, a discount rate increase shifts the sloped portion of the $T \mathbf{R}_{\mathrm{s}}$ curve to the left at al levels of the funds rate. If the borrowings assumption is unchanged, the quantity of nonborrowed reserves must be reduced until the funds rate rises enough to restore borrowings to their desired level. On average, the federal funds rate will change point-for-point with a change in the discount rate under a strictly enforced borrowings procedure.

The same change in the equilibrium federal funds rate could be obtained by changing the borrowings assumption instead. Consequently, changes in the borrowings assumption and changes in the discount rate are substitutes in their effect on the federal funds rate under a strictly enforced borrowings procedure."

Table 1 reports changes in the discount rate and the borrowings assumption from October 1982 through December 1986 . Technical discount rate changes, reportedly made solely to keep the discount rate in line with market interest rates, are denoted by a $\mathrm{T}$; those made for other, policy-related, reasons are denoted by a $P .{ }^{11}$ As the table shows, changes in the borrowings assumption and the discount rate generally occured around the same time: five of the 11 changes in the discount rate came within about one week of a change in the borrowings assumption, while two were within two weeks. Moreover, all changes that occurred close together were in the same direction, indicating consistent movements in both the botrowings assumption and the discount rate.

The table also shows alternating periods of ease and restraint. From October 1982 through the end of the year, the borrowings assumption and the discount rate were reduced. While changes in the borrowings assumption were modest (even cumulatively) and one discount rate change was technical, policy eased moderately during this period.

From spring 1983 to spring 1984, policy moved toward restraint. The borrowings assumption was raised by $\$ 600$ million from March through August 1983 , lowered in October 1983 by $\$ 150$, then increased by $\$ 350$ million in March 1984 . The last increase was followed closely by a 50 basis point technical increase in the discount rate.

Policy was easier during the fall of 1984. The botrowings assumption was reduced by $\$ 700$ million from early October to late December and two policy-related cuts in the discount rate reduced it by a full percentage point. There were no large, consistent movements in the borrowings assumption during 1985 and none after early February 1986, despite four cuts in the discount rate (three of which were policy-related)

\footnotetext{
${ }^{10}$ Because a one percentage-point change in the discount rate is associated with about a $\$ 420$ million change in borrowings over this period, a $\$ 420$ million change in the assumed level of borrowings should have an effect on the funds rate equal to a one percentagepoint change in the discount rate. See Thornton (1986).

"See Thornton (1986, 1982a) for a discussion of the classification of discount rate changes into technical and non-technical changes.
} 


\section{Table 1}

\section{Changes in the Discount Rate and the Borrowings Assumption}

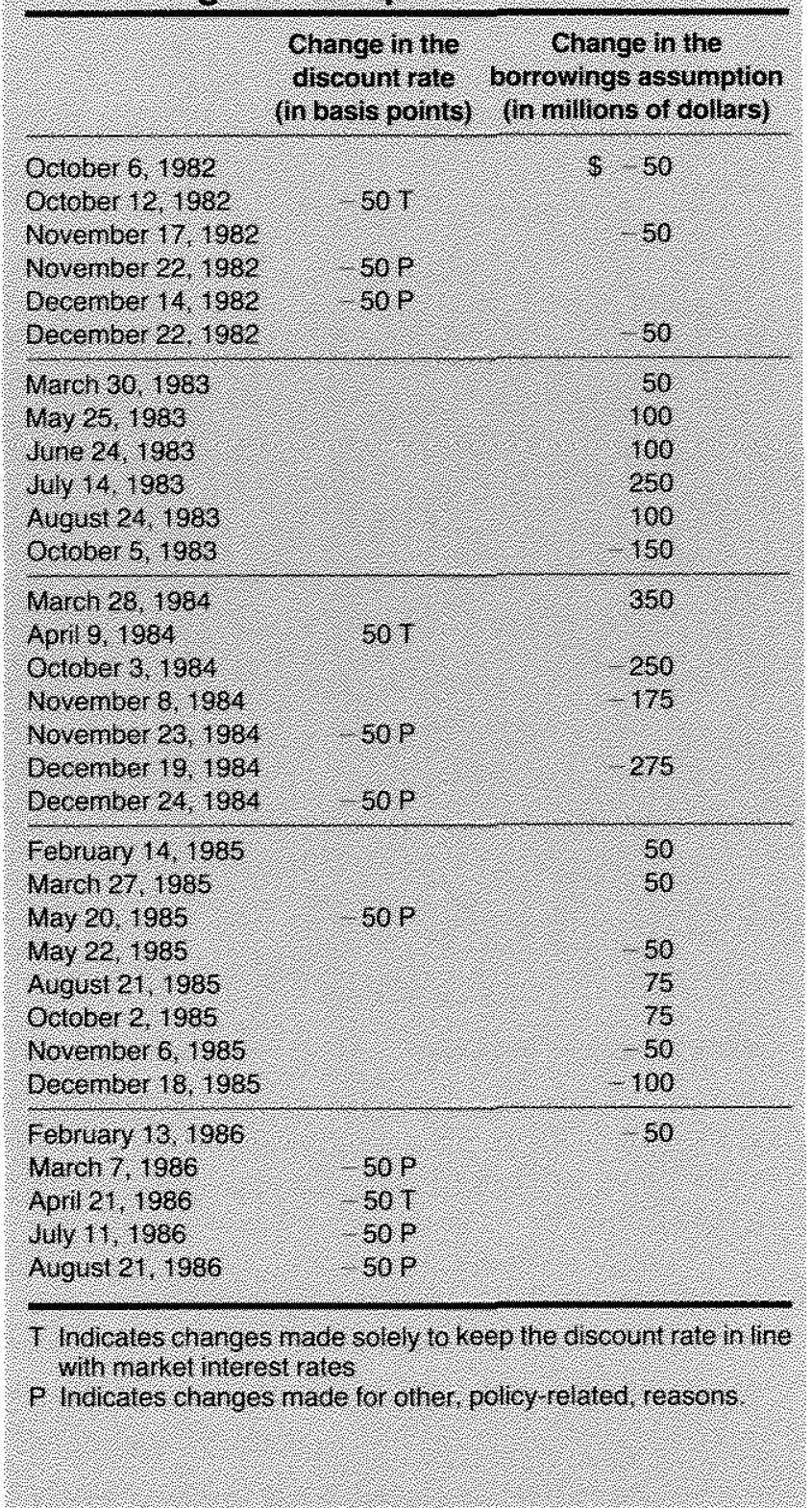

\section{EMPIITCAL EVDENCE ON THE USE OF TIL BORROWNGS PROCEDURE}

An important factor in determining the impact of the borrowings procedure on the funds rate and the money stock is the stability of the borrowings function. Historically, the borrowings function has been subject to considerable random variation: by itself, the spread brtween the federal funds rate and the discount rate explains less than 50 percent of the varia- tion in borrowings about its mean level." For the borrowings procedure to be used effectively as a federal funds rate target over the longer run, the borrowings function must be stable. It is important, therefore, to determine whether there have been permanent shifts in the borrowings function. If so, the key issue is how the borrowings assumption was changed in response to these shifts.

To examine this issue, equation 1 was estimated using random coefficient regression, where both the constant term, $b_{0}$, and the slope coefficient, $b_{1}$ are allowed to vary through time. ${ }^{33}$ Chart 1 presents random-coefficient-regression estimates of the constant term and a band representing plus or minus one standard error. The vertical lines show the dates on which the borrowings assumption was raised or low. ered, as indicated.

The intercept shows considerable variability. With but three significant exceptions, the borrowings assumption was changed in the direction consistent with mitigating the effect of shifts in the borrowings function on the federal funds rate. ${ }^{10}$ The three exceptions occurred in October 1984, August 1985 and October 1985. In October 1984, when the borrowings function shifted upward, the borrowings assumption was reduced from $\$ 1$ billion to $\$ 750$ million. In both August and October 1985, the borrowings assumption was raised, despite the downward shift in the borrowings function. Both increases were relatively small $(\$ 75$ million each), however, and both were completely offset by the mid-December decrease.

These results are consistent with movements in borrowings, the borrowings assumption and the federal funds rate presented in chart 2. The October 1984 change in the borrowings assumption preceded movements in borrowings; however, this action followed a 100 basis-point drop in the funds rate from its

\footnotetext{
12This is for the period from October 1982 through June 11,1986 . See Thornton (1986). This same function estimated for the 222 weeks prior to October 6, 1979 , has an $\overline{\mathrm{R}}^{2}$ of about .70

${ }^{13}$ The procedure used here is suggested by Garbade (1977). The equation was first estmated allowing only the constant term to vary. It was then reestimated allowing both the constant and slope coefficients to vary; this was done to deternire whether variation in the slope coefficient was being inappropriately attributed to the constant term. The results presented in chart 1 are from the latter estimation. The qualitative interpretation of the relationship between changes in the borrowings assumption and shifts in the borrowings function was not affected by the different estimation procedures.

${ }^{14}$ There were two other exceptions: they occurred on October 6, 1982, and May 22, 1985. In both instances, however, these changes predate the shift by only one week. Iroluding these in subsequent statistical tests does not affect the results.
} 
Chort 1

Varying Parameter Intercept

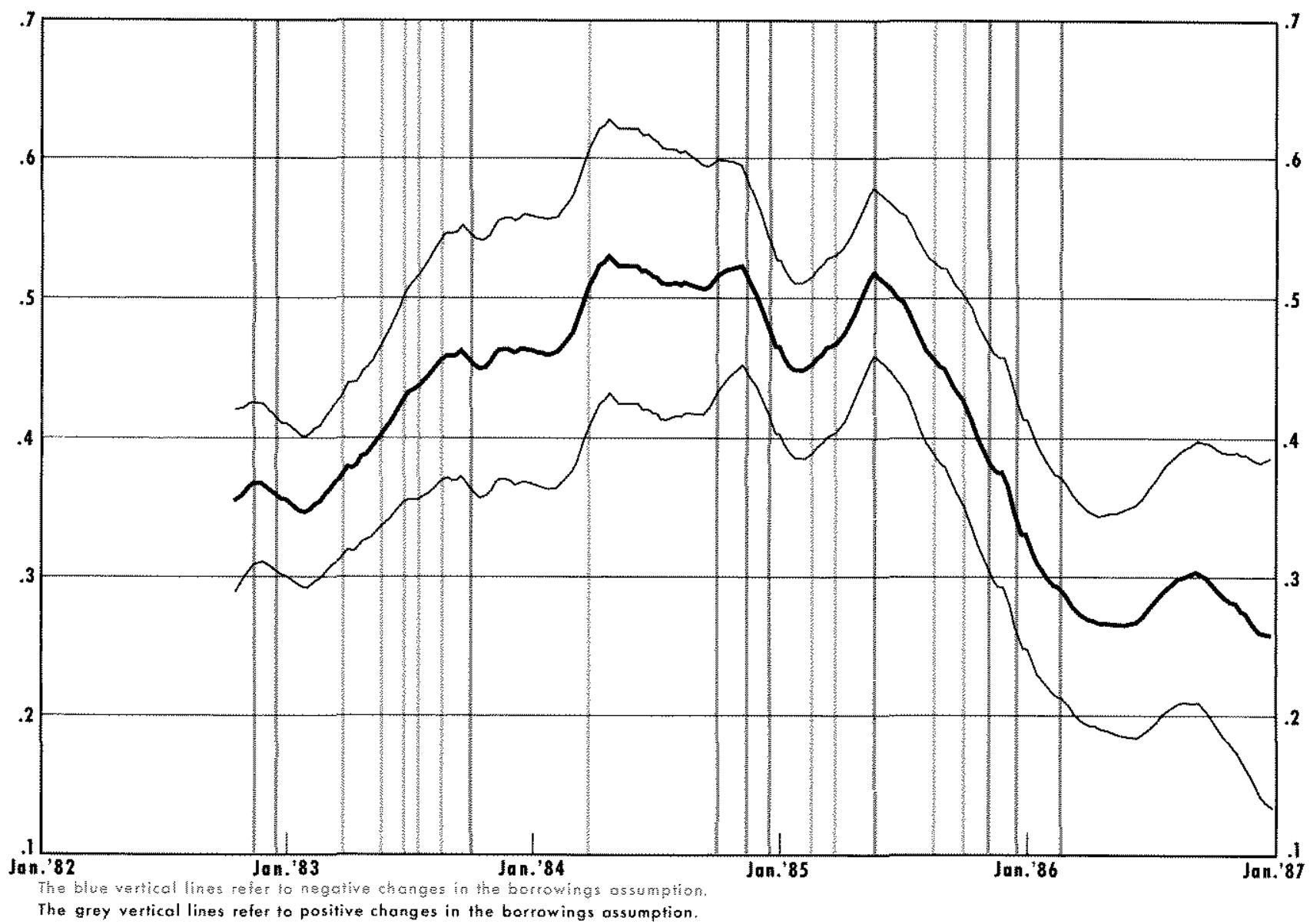

cyclical peak for the week ending August $22 .^{15}$ Nearly all other changes in the borrowings assumption were preceded by movements in borrowings and the federal funds rate in the same direction.

\section{Compartson of the Variabilly of Bowowings and the Federal huds Rate}

Further evidence on the effects of using the borrowings procedure can be obtained by analyzing scatter plots of borrowings and the federal funds rate during periods in which both the borrowings assumption

\footnotetext{
15The FOMC meeting was held on October 2,1984 . The federal funds rate had fallen to 9.84 percent on September 26 , though it averaged 10,73 percent for the week ending Wednesday, September 26 . The weekly peak was 11.77 percent for the week ending Wednesday, August 22; the daily peak occurred on August 1 , when the federal funds rate was 12.04 percent.
}

and the discount rate were unchanged ${ }^{16}$ The previous results suggest that there are considerable temporary shifts in the demand for borrowed reserves. If most of the effect of short-run variation in the borrowings function on the federal funds rate were offset quickly, there would be little variation in the federal funds rate but considerable variation in borrowed reserves. In the extreme, if the effect of all such shifts on the funds rate were quickly and completely offset, all observations would lie along a vertical line representing the average of the federal funds rate in a scatter plot of borrowings and the federal funds rate. On the other hand, if borrowings were kept close to the assumed

\footnotetext{
${ }^{16}$ This procedure was suggested to me by R. Alton Gilbert, It is interesting to note that the variability of borrowings could be reduced by simply "tying" the discount rate to the federal funds rate. This point was made by Thornton (1982b) and more recently by Vanthoose (1987).
} 
Chart 2

Borrowings, Borrowings Assumption, and Federal Funds Rate

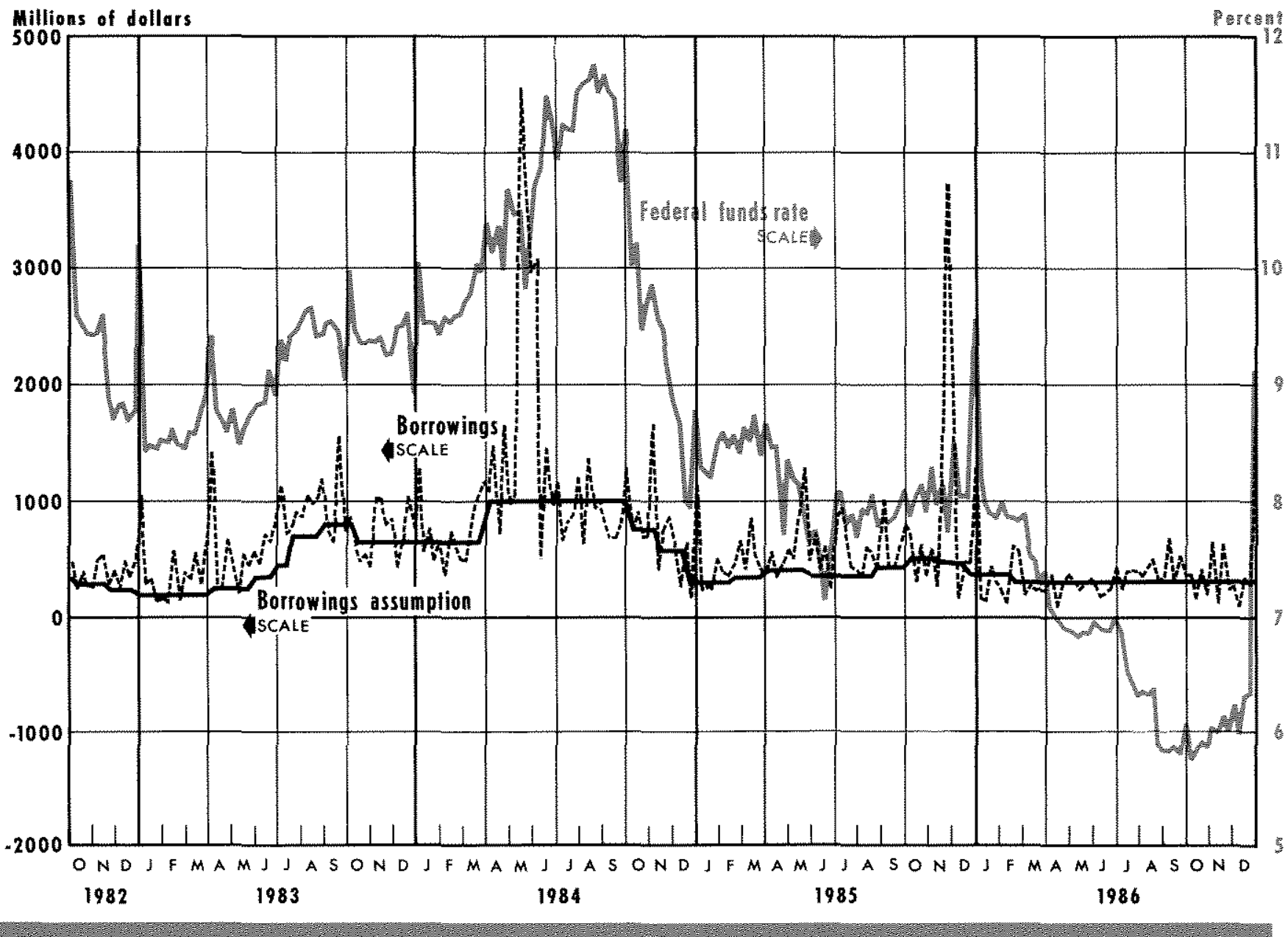

level, the funds rate should vary relatively more than bortowings. In this case, the observations should be chustered about a horizontal line at the assumed level for borrowings."

During the post-October 1982 period, there were six periods with 10 or more weeks in which both the bortowings assumption and the discount rate were unchanged." Scatter plots of borrowings and the fedearal funds rate for these periods are presented in

17The variability of borrowings and the funds rate depend on the slopes of the $T \mathrm{P}_{\mathrm{s}}$ and $\mathrm{TR}_{\mathrm{d}}$ curves and the extent to which random shocks are offset. If more than 50 percent of such shocks are offset during the period, however, there will be more variability in the funds rate than in borrowings regardless of the slopes of these curves.

:PPlots for the omitted periods show no pattern. They consist, however, of very few observations. charts $3 a$ through 3f." The data used in these charts have been nomalized. The actual level of borrowings was normalized by dividing it by the level of the borwowings assumption for the respective period. The federal funds rate was normalized by dividing it by its average rate for the period." All charts have identical scales for both variables to make it easy to compare the relative variability. The solid horizontal and vertical lines denote where the normalized variables are equal

:These data exclude outliers such as the "window-dressing" borrowings during the final reserve period of the year and the unusually large borrowings associated with Continental Bank of lllinois. See Thornton (1986) for a discussion of the fatter episode.

${ }^{20}$ Because the mean of the normalized rate spread equals one the rate spreads will be scattered symmetrically about the vertical line. In contrast, the data points will be scattered asymmetrically above (below) the vertical line depending on whether the borrowings assumption is below (above) the average level of borrowings for the period. 
Chart 3

\section{Selected Scatter Plots of Normalized Borrowings}

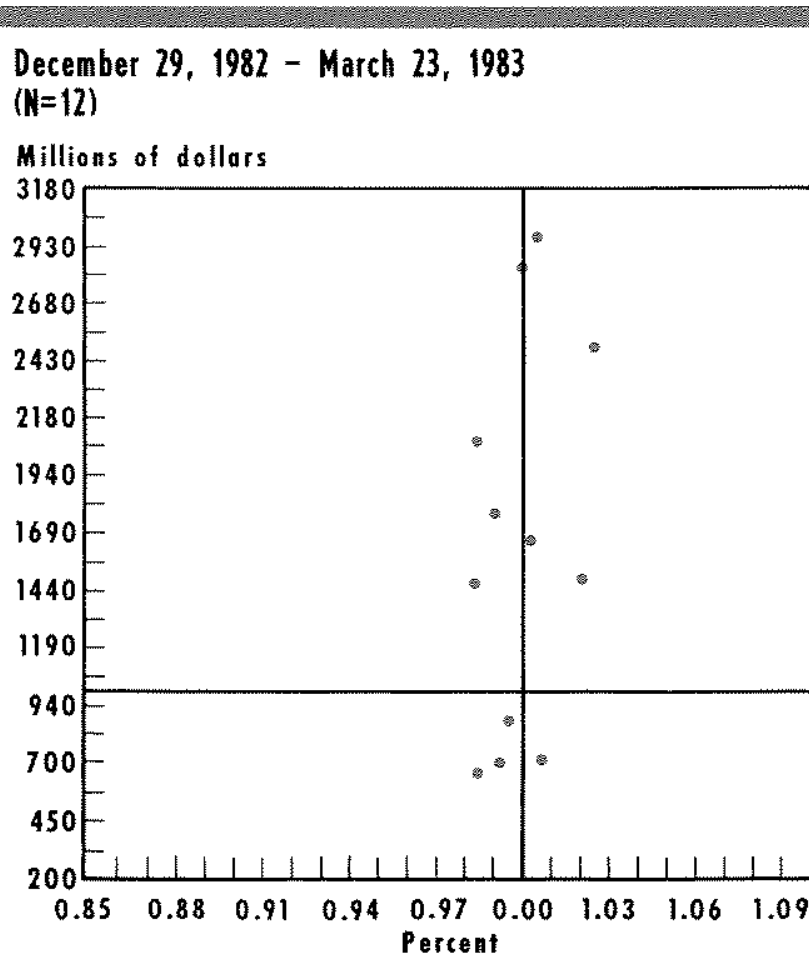

(a)

\section{April 18, 1984 - September 26, 1984 \\ (II $=20)$}

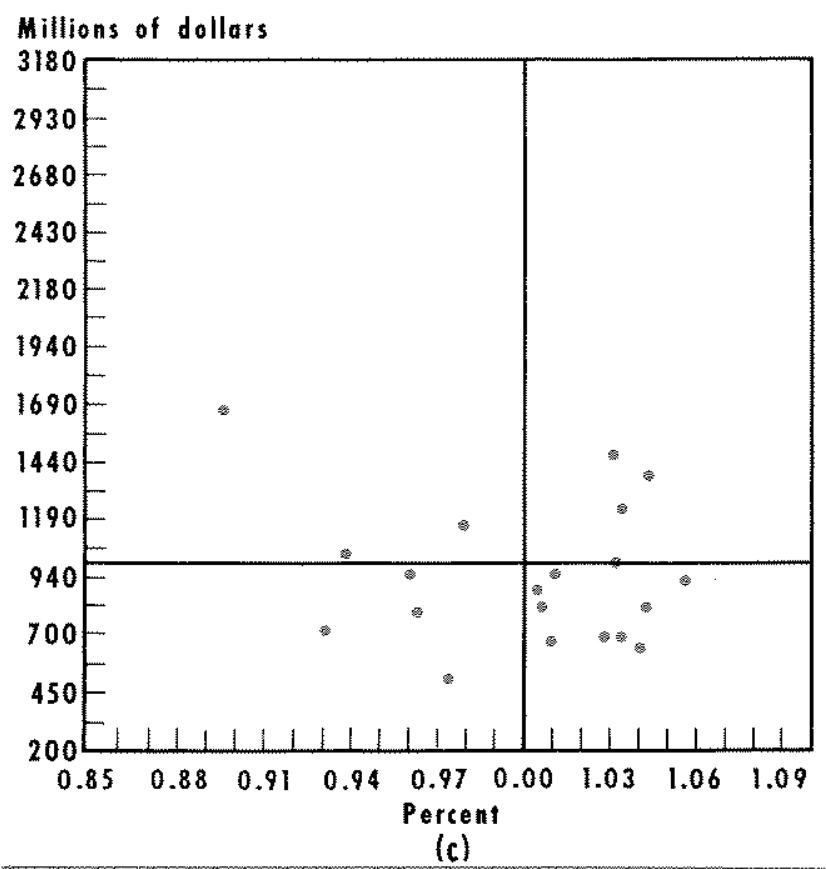

October 12, $1983-$ Marcli 21, 1984

$(\mathrm{N}=23)$

Millions of dollars

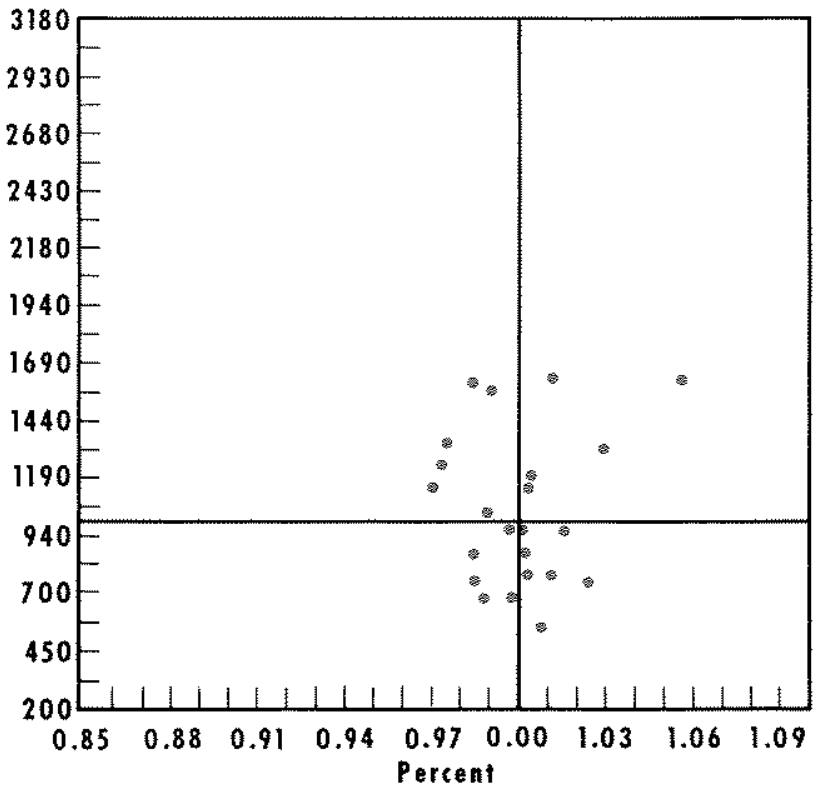

(b)

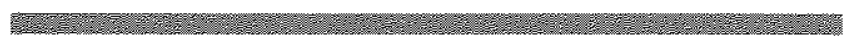

\section{May 29, 1985 - August 14, 1985}

$(\mathrm{N}=12)$

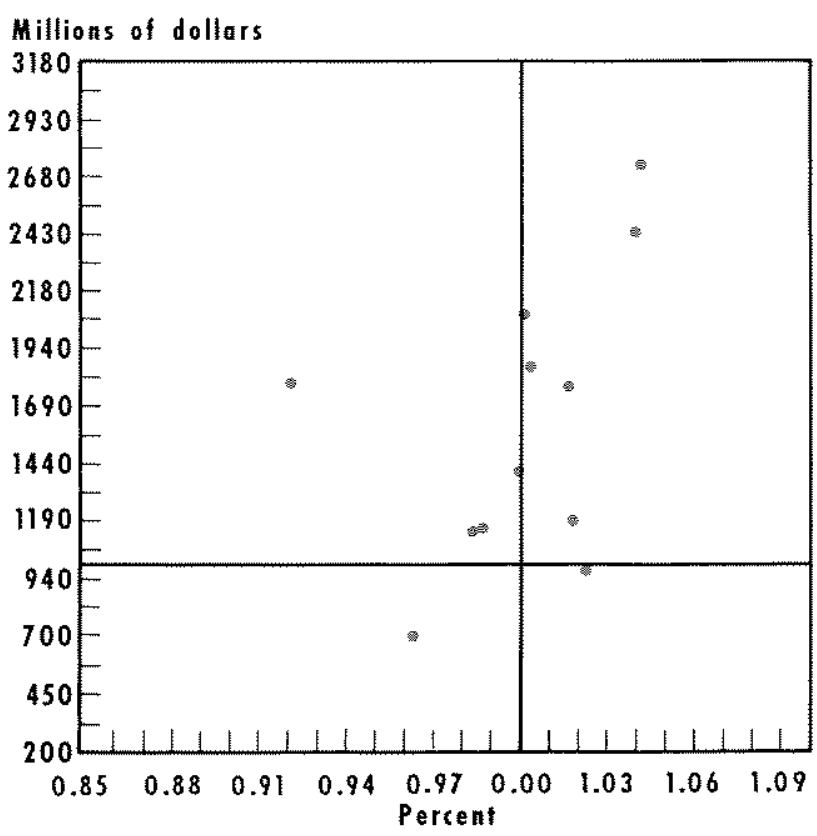

(d)

The vertical reference lines refer to the normalized mean of the federal funds rate; the horizontal reference lines refer to the normalized mean of borrowings. 


\section{and the Normalized Federal Funds Rate}

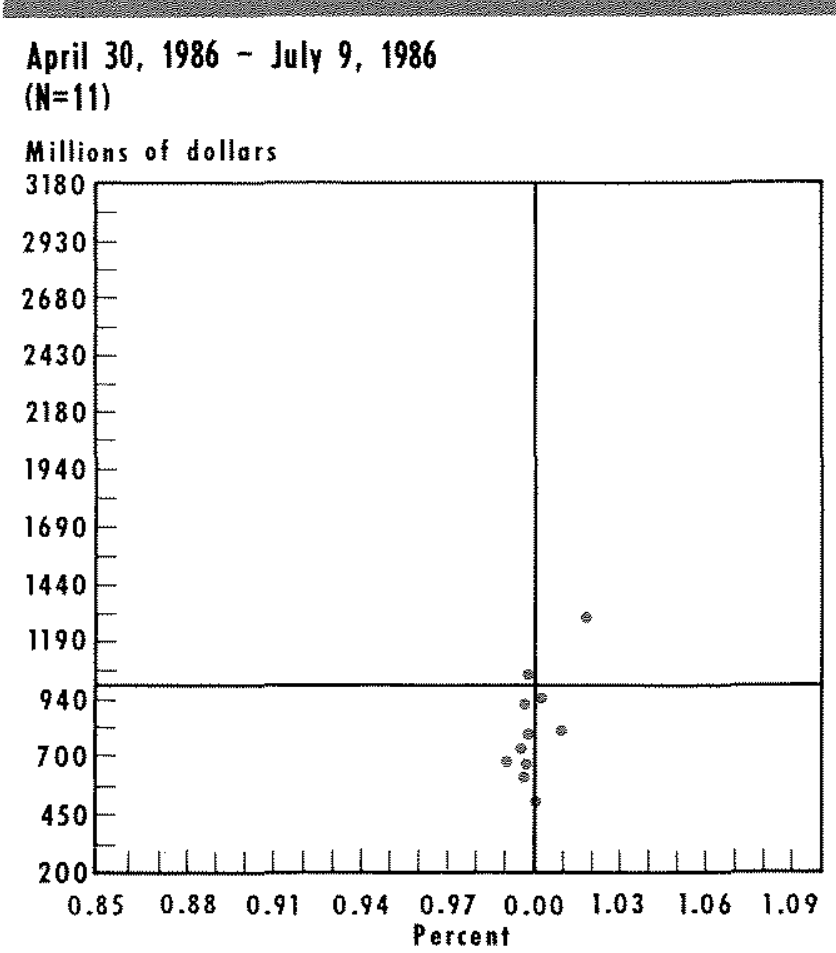

(e)

December 27, 1978 - July 18, 1979

$(\mathrm{H}=30)$

Millions of doflats

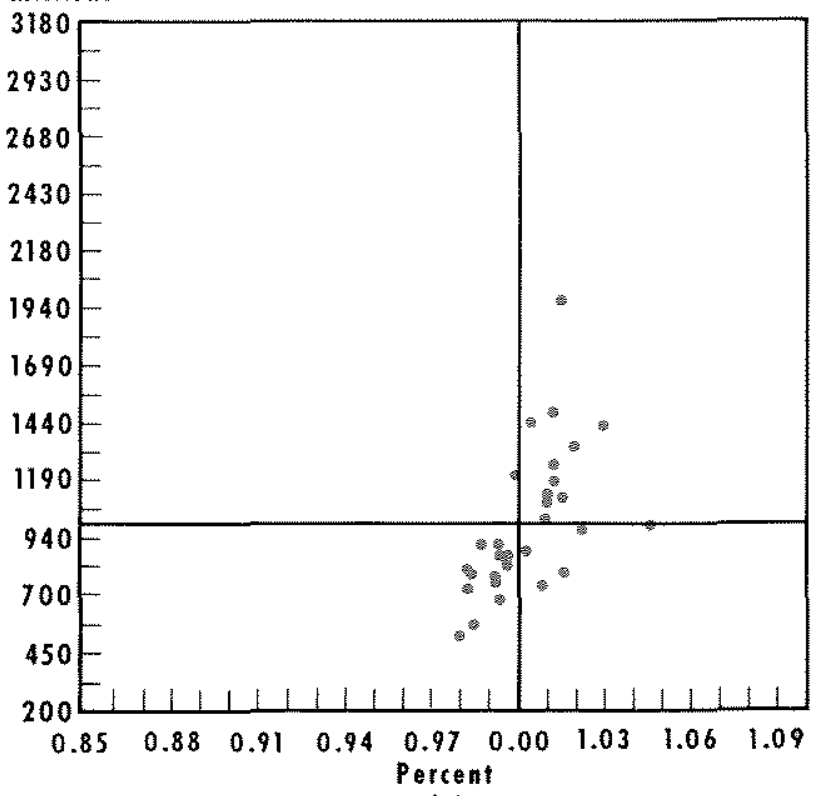

(g)

\author{
August 21,1986 - December 24, 1986 \\ $(N=18)$
}

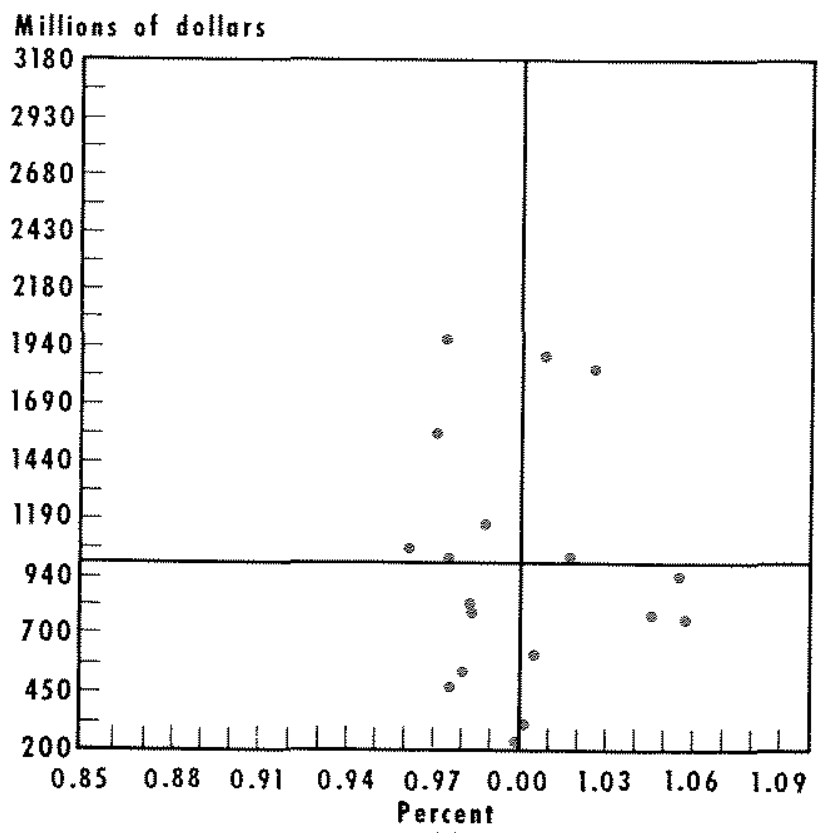

(f)

to one Some descriptive statistics for the raw data are presented in table 2 .

Finally, chart $3 \mathrm{~g}$ is a scatter plot from late December 1978 to late July 1979 , when it is generally acknowledged that the Fed was targeting the federal funds rate. During this period, a 75 basis-point target range for the federal funds rate was specified."1

With the exception perhaps of chart $3 c$ no period suggests a rapid adjustment to maintain borrowings at the assumed level. In contrast, two periods /charts $3 a$ and $3 e$ show relatively litle variability in the fed eral funds rate. Indeed, a comparison of these charts with chart $3 g$ shows that the funds rate fluctuated less around its mean during these periods than it did around the midpoint of the Fed's narrow range for the federal funds rate in early 1979.

There should be less variability in borrowings and more variability in the federal funds rate under a

${ }^{21}$ This was the only extended period in which the federal funds rate band was both narrow and unchanged. 


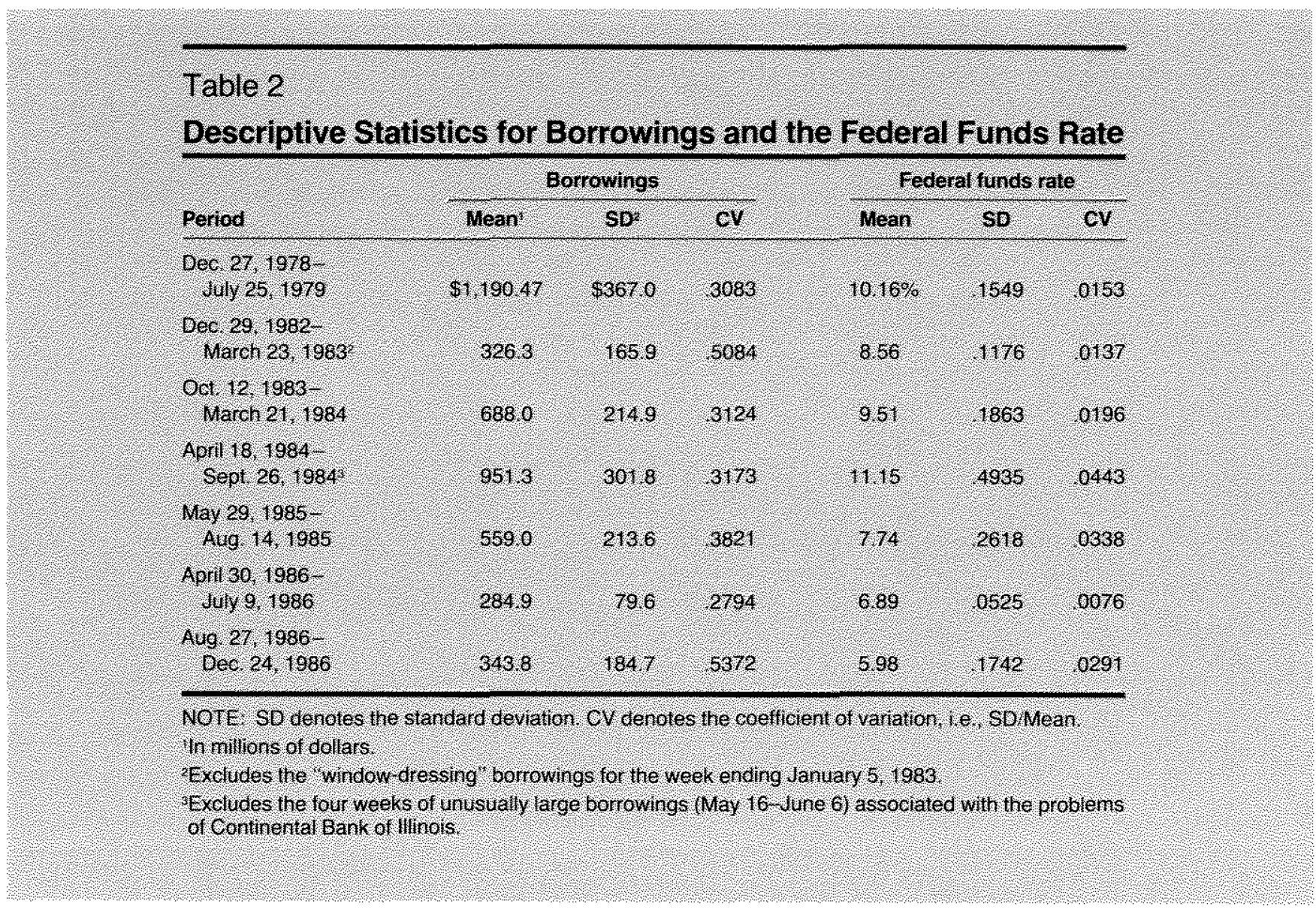

borrowings target than under an interest rate target Table 3 presents the mean, standard devation (SD) and a measure of relative variability, the coefficient of variation (CV), for weekly data during the period of the borrowings operating procedure and during an equal number of weeks under an interest-rate-targeting regime. The results are generally consistent with those discussed above. The variability of borrowings differs little in either absolute or relative terms between the two periods. The variability of the federal funds rate, however, fell considerably; its SD declined nearly 30 percent, while its $C V$ declined nearly 50 percent.?

\section{The rmpart of changers in the

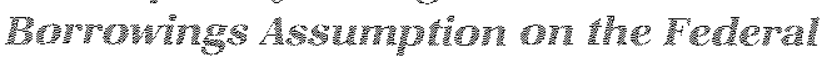 Thinds rinte}

If changes in the borrowings assumption were made primarily to offset shifts in the borrowings function, there should be no significant relationship be

\footnotetext{
2? This result is only marginally affected by the switch from a one-week to a two-week reserve accounting period. If only reserve period data are used for the CRR period, the standard deviation of the funds rate is 1.60 percent and the coefficient of variation is .19 .
}

tween changes in the bortowings assumption and movements in the federal funds rate. If changes in the borrowings assumption are made for other reasons, they should produce a significant effect on the federal funds rate:

\footnotetext{
${ }^{23}$ This is true only if a discount rate change shows significant direct effect on the federal funds rate; Thornton (1986) argues such an effect should be small and insignificant. Indeed, this may provide an expectations"effect-free method of assessing the direct effect of a discount rate change on market interest rates. See Thornton (1986) for discussion of three potential effects of a change in the discount rate on the federal funds rate
}

Because the Federal Reserve makes a public statement when it changes the discount rate, it is difficult to separate the direct and announcement effects. In contrast, the levels of the borrowings assumption for the previous calendar year are made public in the Spring issue of the Federal Reserve Bank of New York Quarterly Review. Because appropriately scaled changes in the discount rate and the borrowings assumption have equivalent announcementfree effects on the supply of credit in the market, the direct effect of discount rate changes can be gauged by investigating the effect of changes in the borrowings assumption if the Federal Reserve moves quickly to stabilize the level of borrowings at the new assumed level. If changes in the borrowings assumption are made to offset the effect of shifts in the borrowings function on the federal funds rate, they will not produce a significant effect on the federal funds rate and will not provide an announcement-effect-free test of the direct effect of a discount rate change. 
To investigate this, the following equation was estimated:

$$
\begin{aligned}
& \text { I. } \\
& \text { (3) } \Delta \text { FFR }_{\mathrm{t}}=\alpha_{13}+\sum_{i=1}^{\sum} \alpha_{i} \Delta \mathrm{FFR}_{\mathrm{i}-\mathrm{i}}+\beta_{i} \Delta \mathrm{DPT}_{\mathrm{t}} \\
& +\beta_{1} \Delta \mathrm{DRNT}_{\mathrm{i}}+\sum_{i=0}^{\mathrm{K}} \mu_{i} \Delta \mathrm{BA}_{\mathrm{i}-\mathrm{i}}+\varepsilon_{\mathrm{s}} .
\end{aligned}
$$

Here, $\triangle$ FFR denotes the change in the federal funds rate, $\triangle D R T$ and $\triangle D R N T$ denote "technical" and "nontechnical" changes in the discount rate, $\triangle \mathrm{B} A$ denotes the changes in the borrowings assumption and $\varepsilon$ denotes a random error term. A change in the borrow ings assumption was assumed to be effective the day after the decision was made..- This equation was estimated using ordinary least squares (OLS) for the period from October 1, 1982, through December 31, 1986; however, the equation was estimated separately for the period of lagged reserve requirements, Lhe tup to February 1,1984 ) and contemporaneous reserve requirements, CRR." The equation was estimated using daily, weekly and reserve-period data cone week before February 1, 1984, and two weeks thereaftery.

Because it is not known how quickly changes in the borrowings assumption are implemented or how rapidly the federal funds rate might respond, lags of $\Delta \mathrm{BA}$ were included; however, the F-statistic for including lagged values of the $\triangle B A, F_{A B w+s ;}$ shows that the relationship between the $\triangle F F R$ and $\triangle B A$ is contemporaneous regardless of whether daily, weekly or reserveperiod data are used. ${ }^{25}$

The results are reported in table 4 . They indicate a statistically significant positive relationship between changes in the funds rate and changes in the borrowings assumption only for weekly data during the CRR period. A further investigation of this relationship, however, shows it to be quite fragile /see appendix $\mathbf{B}$

\footnotetext{
${ }^{24} \mathrm{All}$ changes in the borrowings assumption but one were made at regularly scheduled meetings of the FOMC.

${ }^{25}$ The equation was estimated for separate periods for several reasons. First, it would be inappropriate to estimate the equation using reserve-period data for the entire sample period with OLS because the error lerms of one-week and two-week average data will be different and OLS would not reflect the heteroskedasticity induced by the change in the reserve accounting period. Second, the coefficients do not appear to be stable over the entire period as the resutts of table 4 suggest. Third, there is a pronounced quarterly seasonal spike during the LRR period (as is readily evident in chart 2) that is not statistically identifiable during the CAR period. Finally, there is low-order autocorrelation in the error term during the CRR period which is not evident during the LRR period.

${ }^{25}$ The exception was for daily data during the CRR period; however, the sum of the coefficients was not significantly different trom zero.
}

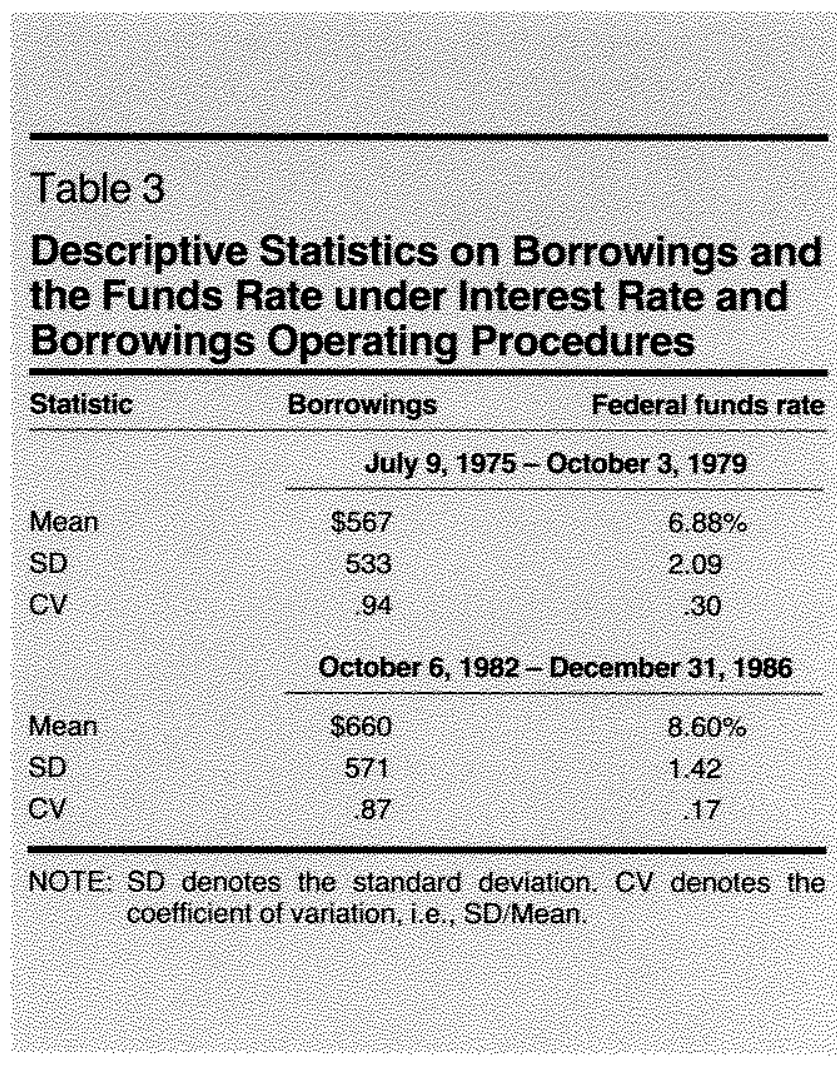

for details). Hence, there is no strong, statistically significant relationship between changes in the borrowings assumption and changes in the funds rate. These results are consistent with the previous ones that changes in the borrowings assumption were made primarily to accommodate shifts in the borrowings function. 37

\section{SUMMATY AND CONCLUSIIIS}

This paper assesses the usefulness of the borrowings operating procedure in controlling the money stock or the interest rates. The borrowings procedure is a poor method for achieving money stock control. In fact, a federal funds rate targeting procedure is superior for both money stock and interest rate control.

The borrowings procedure is an effective means of targeting the federal funds rate in the short run only when the variation in borrowings is due solely to shifts in the demand for total reserves. It is an effective means of largeting the federal funds rate over longer periods only when the borrowings function is stable. If there are permanent shifts in the borrowings function,

\footnotetext{
${ }^{27}$ Alternatively, these results could be interpreted as evidence that the announcement-free, "direct effect" of a discount rate change on the federal funds rate is nil.
} 


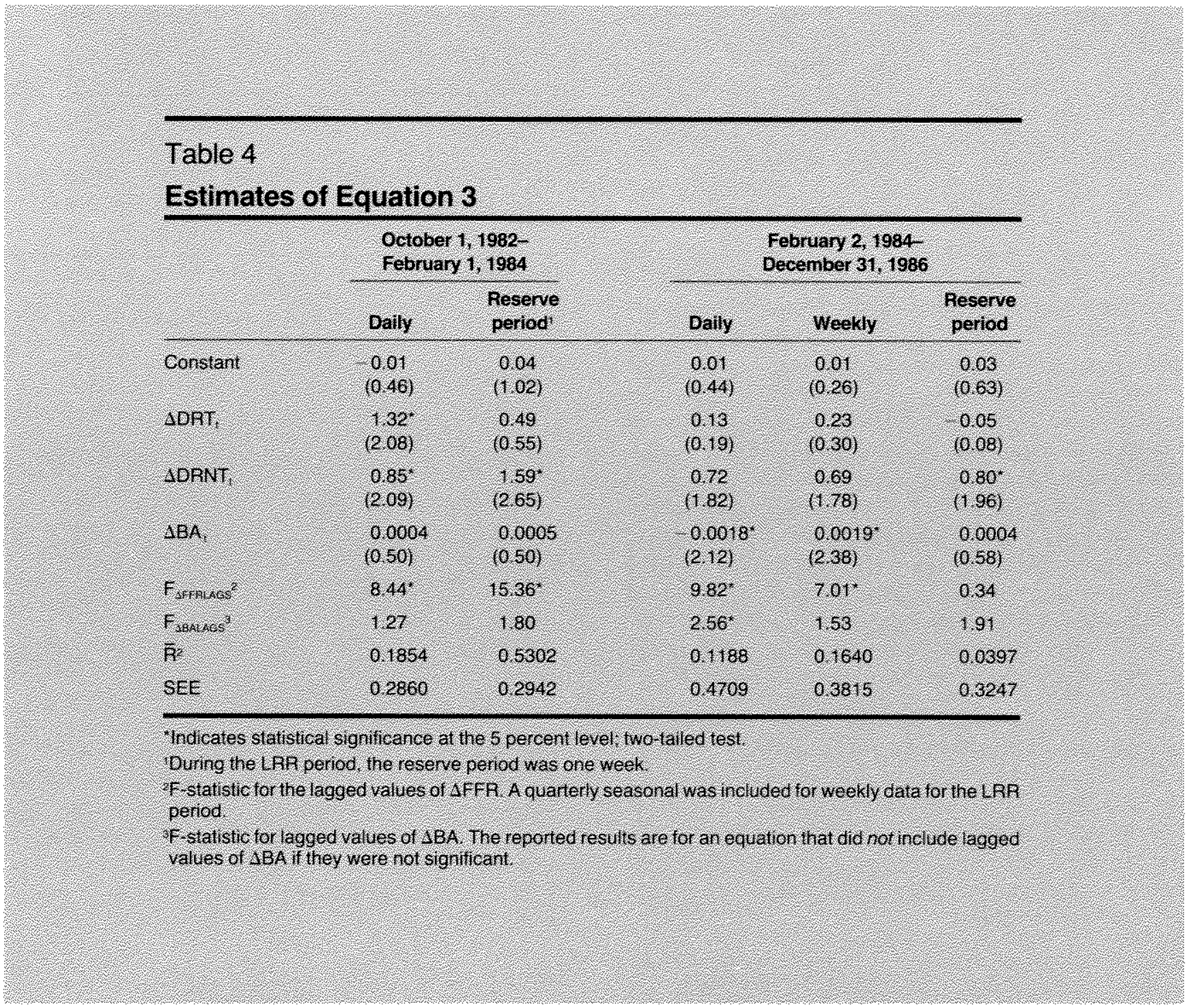

the federal funds rate will vary with shifts in the borrowings function, and the borrowings procedure can be used to target the federal funds rate only if compensatory changes in the borrowings assumption are made.

Evidence indicates that the borrowings function is unstable. Also, it suggests that generally the borrowings assumption has been changed in the direction. that offsets the effect of permanent shifts in the borrowings function on the federal funds rate.

\section{FERERENCES}

Board of Governors of the Federal Reserve System. "The Federal Reserve Discount Window," 1980.

Dickey, David A., and Wayne A. Fuller. "Distribution of the Estima" tors for Autoregressive Time Series With a Unit Root," Joumal of the American Statistical Association (fune 1979), pp. 427-31.

Engle, Robert F., and C. W. J. Granger. "Co-integration and Error Correction: Representation, Estimation, and Testing," Economefrica (March 1987), pp. 251-76.
Federal Reserve Bank of New York. "Monetary Policy and Open Market Operations in 1985," Quarferly Review (Spring 1986), pp. $34-53$.

Garbade, Kenneth. "Two Methods for Examining the Stability of Regression Coefficients," Journal of the American Statistical Association (March 1977), pp. 54-63.

Gilbert, R. Alton. "Operating Procedures for Conducting Monetary Policy," this Review (February 1985), pp. 13-21.

Goodfriend, Marvin. "Discount Window Borrowings, Monetary Policy, and the Post-October 6, 1979 Federal Reserve Operating Procedure," Joumal of Monetary Economics (September 1983 ), pp. $343-56$.

Plosser, Charles 1. G. William Schwert and Halbert White. "Differencing as a Test of Specification," International Economic Review (October 1982), pp. 535-52

Polakoff, Murray E. "Reluctance Elasticity, Least Cost, and Member-Bank Borrowing: A Suggested Integration," Joumal of Finance (March 1960), pp. 1-18.

Riefler, Winfield. Money Rates and Money Markets in the United States (Harper and Brothers, 1930).

Roley, V. Vance. "Marke: Perceptions of U.S. Monetary Policy since 1982," Federal Reserve Bank of Kansas City Economic Review (May 1986), pp. 27-40. 
Thornton, Daniel L. "The Discount Rate and Market Interest Rates: Theory and Evidence," this Review (August/September 1986), pp. 5-21.

"Lagged and Contemporaneous Reserve Accounting An Atternative View," this Review (November 1983). pp. 26-33.

"The Discount Rate and Market Interest Rates: What's the Connection?" this Review (June/July $1982 a$ ), pp. 3-14.

:Simple Analytics of the Money Supply Process and Monetary Controt," this Review (October 1982b), pp. 22-39.
VanHoose, David D. "A Note on Discount Rate Policy and the Variability of Discount Window Borrowing:" Joumal of Banking \& Finance (December 1987), pp. 563-70

"Discount Rate Policy and Alternative Federal Reserve Operating Procedures in a Rational Expectations Setting," Board of Governors of the Federal Reserve System, Finance and Economics Discussion Series, 12 (February 1988 ).

Wallich, Henry C. "Recent Techniques of Monetary Policy," Federal Reserve Bank of Kansas City Economic Review (May 1984). p. $21-30$.

\section{Appendix A \\ Complete Results for a Simple Model of the Reserves Market}

This appendix develops the results stated in the text in terms of a simple model of the money stock. The model consists of the following equations:

(A1) $\mathrm{TR}_{d}=a_{\mathrm{d}}-\mathrm{a}_{\mathrm{k}} \mathrm{FFR}+\mathrm{u}$

(A2) Borr $=b_{0}+b_{1}($ FER - DR $)+v$

(A3) $\mathrm{TR}_{\mathrm{s}}=\mathrm{NBR}+\mathrm{BOH}$

and

(A4) $\mathrm{TR}_{\mathrm{d}}=\mathrm{TR}$

where TR denotes total reserves and the subscripts "d" and " $s$ " denote "ctemand" and "supply." Bor denotes the amount of borrowings and NBR the supply of nonborrowed reserves, which is assumed to be controlled by the Fed. FTt and DR denote the federal funds and discount rates, respectively, and $u$ and $v$ are andom errors such that E(u) $=\mathrm{E}(\mathrm{v})=\mathrm{E}(\mathrm{uv})=0$. Equations $A 1$ - A4 can be combined to yield the expression for the equilibrium federal funds rate

(A5) $F F R=-\lambda^{-3}\left[N B R+\left(b_{0}-a_{1}\right)-b_{1} D R+(w-u)\right]$

where $\lambda=\left(a_{1}+b_{1}\right)$. Figure A1-a shows the expected value of this equilibrium equation." Given the discount rate and the structural parameters, it shows all possible combinations of FFR and NBR such that the reserve market is in equilibrium. Figure A1-b reflects the expected value of the borrowings function, equation A2.

\footnotetext{
The "ime" subscript, $t$, is dropped for convenience.
}

2The curve stopes downward on the assumption that the interest rate intercept is positive. A sufficient condition for this is that $a_{0}>b_{0}$.
If the Fed establishes a borrowings objective, Borr*, the federal funds rate must equal FFR*, given the discount rate. The equilibrium trade off curve indicates that the target level of borrowings can be hit by providing nonborrowed reserves equal to $\mathrm{NBR}^{*}$. This illustrates the relationship between a borrowings operating procedure and a federal funds rate targeting procedure. If the Fed does not respond to stochastic shocks, the variance of borrowings will be identical under either procedure, as will the variance of the federal funds rate.

Differences between the two procedures emerge when the Fed acts to offset disturbances in borrowings, $v$. The results depend on the time period over which the disturbances are operative and the assumption made about the distributions of $u$ and $v$. For example, if shocks occur each day and if $v$ and $u$ are white noise, such shifts essentially will be impossible to offset. Furthemore, because $\sum_{i=1}^{n} u_{i} / n$ and $\sum_{i=1}^{n} \quad v_{i} / n$ approach zero as ngets large, there is no need to offset these shifts if the planning horizon is fairly long. Over shorter periods such as a reserve period lone week before February 1984 and two weeks thereafter, these emors will seldom "average out;" therefore, it may be desirable to offset part of these shocks. Also, these shocks may exhibit persistence, e.g, $\mathbf{u}_{1}=\varphi_{1} u_{\mathrm{t}-1}+\varepsilon_{1}$ and $v_{1}=\varphi_{2} v_{1-1}+\eta_{1}$, when $\varepsilon_{\mathrm{a}}$ and $\eta_{1}$ are white noise. In this case, the fed may also find it advantageous to offset some shifts during the reserve period lor, for that matter, over a somewhat shorter or longer period! depending on the magnitude of $\varphi_{1}$ and $\varphi_{2}$. 


\section{Figure A1}

\section{Equilibrium in the Reserve Market under a Borrowings Procedure}

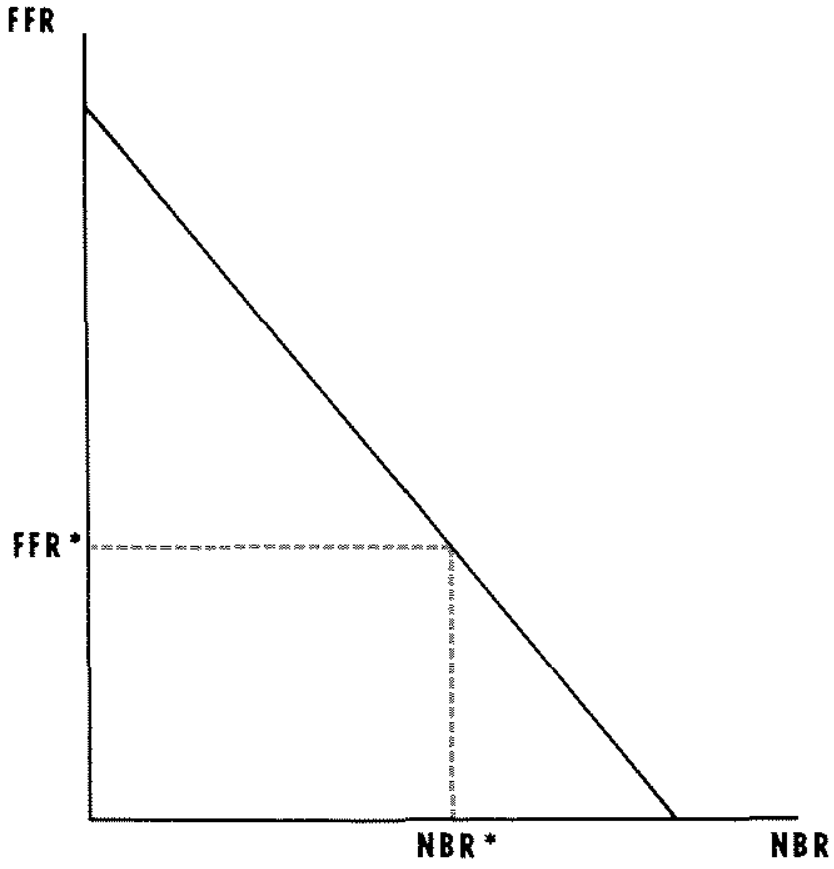

(a)
FFR

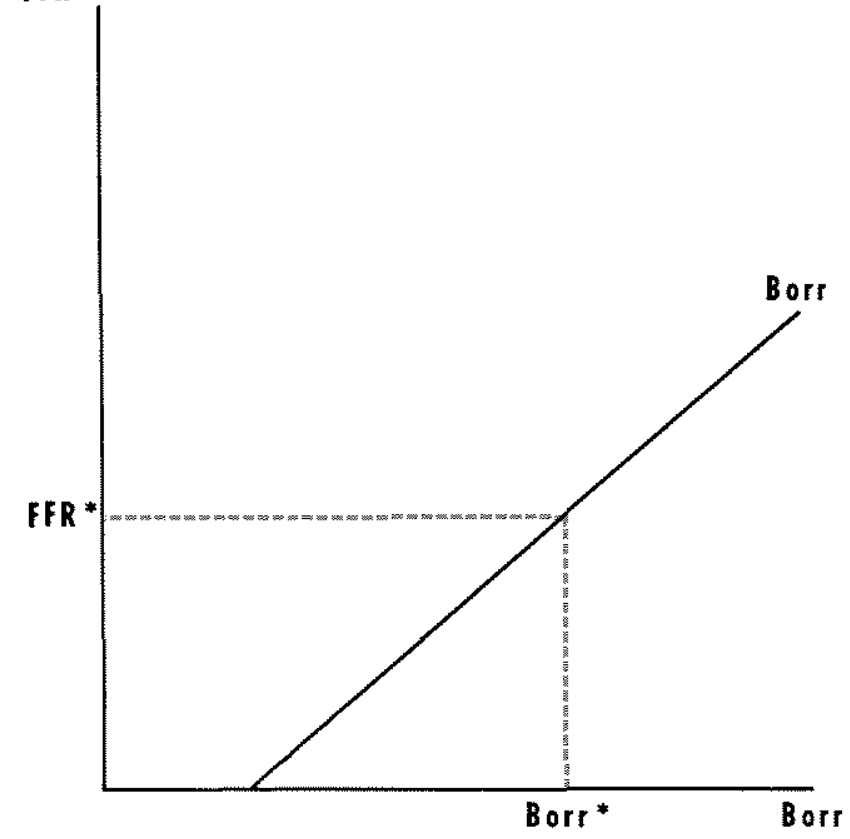

(b)

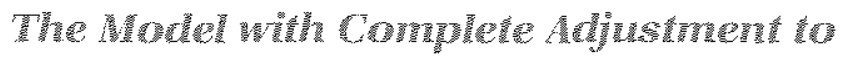 Shucks}

The borrowings operating procedure can be differentiated from an interest rate targeting procedure by comparing the appropriate response to shocks in either borrowings or the federal funds rate under each procedure. Initially, this is done under the assumption that the fed completely offsets all shocks.

Under the borrowings procedure, the appropriate response to shocks is to change nonborrowed re. serves in accordance with the rule:

(AG) $\mathrm{dNBR}=\mathrm{u}+\left(\mathrm{a}_{\mathrm{r}} / \mathrm{b}_{1}, \mathrm{~N}^{3}\right.$

Thus, nonborrowed reserves should change dollar for collar with a shock to the demand for total reserves and by a larger or smaller amount (depending on the relative magnitudes of $a_{1}$ and $b_{2}$, for a shock to borrow-

${ }^{3}$ This rule is obtained by substituting $A 5$ into $A 2$, totally differentiating the result and setting it equal to zero. Technically, the result is dNBR $=d u+\left(a_{d} / b_{1}\right) d v$; however, since the results are presented about the expected value, du and $d v$ have been replaced with $u$ and $v$. ings. These cases are illustrated in figures $\mathrm{A}_{2}$ and $\mathrm{A3}$. In figure $A 2$, fully anticipated increase in the demand for total reserves shifts the market equilibritum cuve by $u$; the borrowings function remains unaffected by this shock, Consequently, the target level of the federal funds rate is unchanged, but NBR is increased by $u$.

In figure $A 3$, a positive value of $v$ shifts the borrowings function to the right by $v$ and the market equilibriam curve to the left by $v$. As a result, the level of the funds rate that is consistent with the borrowings objective is lower and nonborrowed reserves must be expanded by $(a, b$, to bring the funds rate down enough to maintain borrowings at the target level. If the Fed fully offsets shifts in the demand for total reserves, neither borrowings nor the funds rate will change. If the borrowings function shifts, however, borrowings would remain at their target level but the federal funds rate will change.

Under a federal funds rate targeting procedure, the appropriate rule for adjusting nonborrowed reserves would be

$(A 7)$ dNBR $=u \cdots v$

Note that the response to a shock in total reserves demand is the same as under the borrowings operat- 
Figu re $A 2$

The Effect of a Rise in $v$ under a Borrowings Operating Procedure

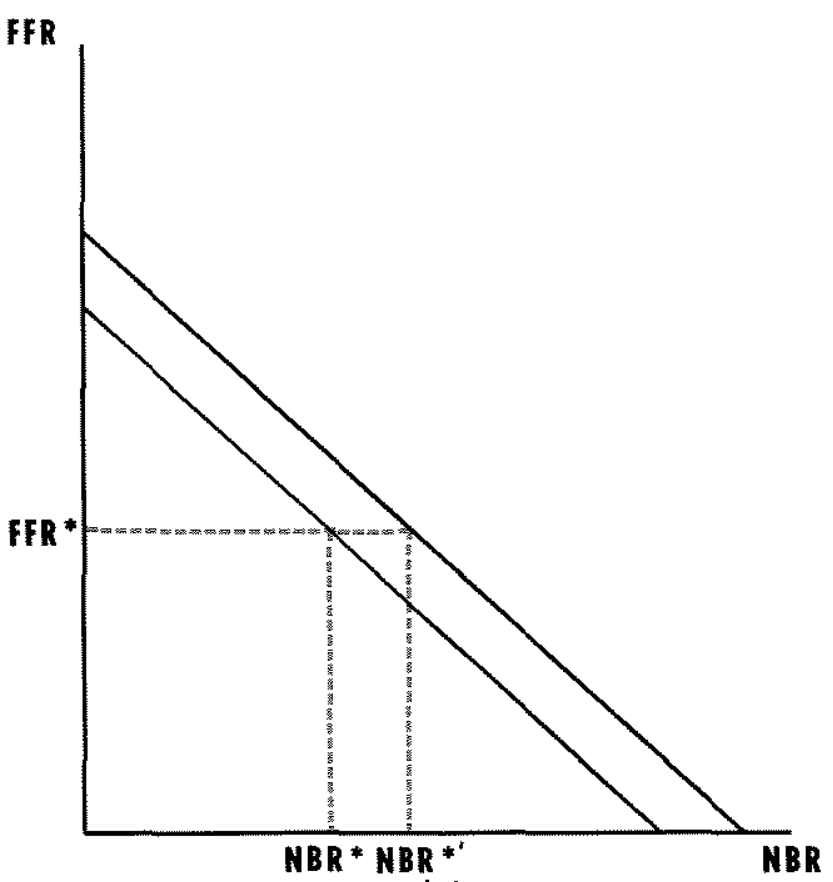

(a)

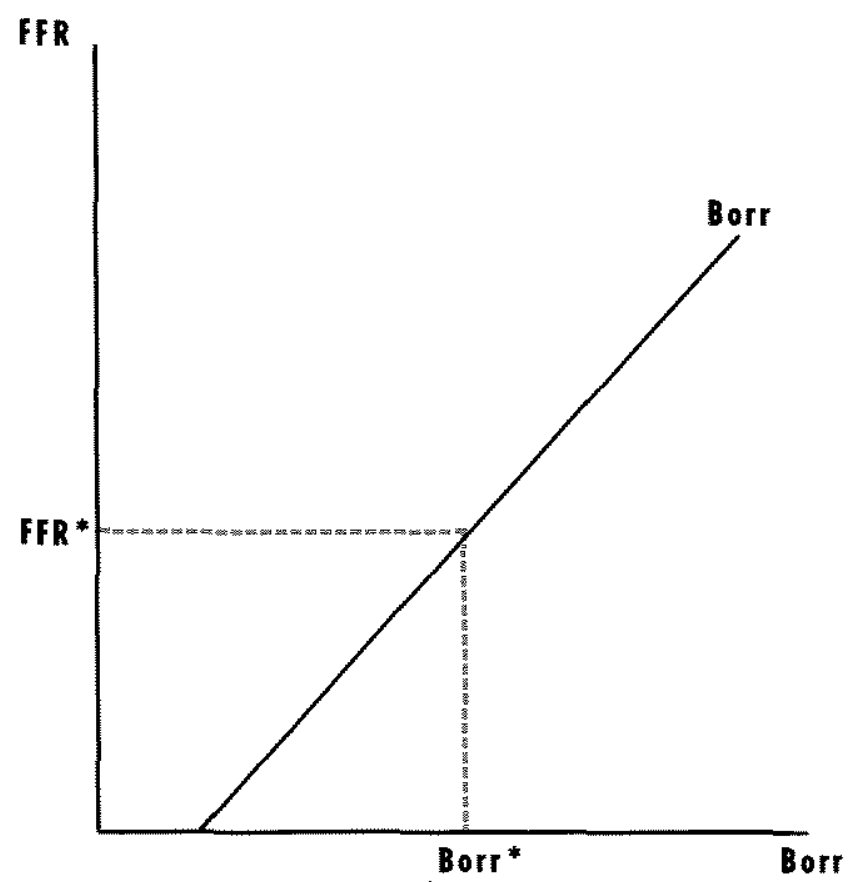

(b)

r.

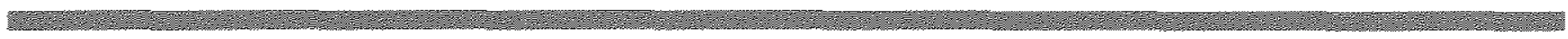

Figure A3

The Effect of a Rise in $v$ under a Borrowings Procedure

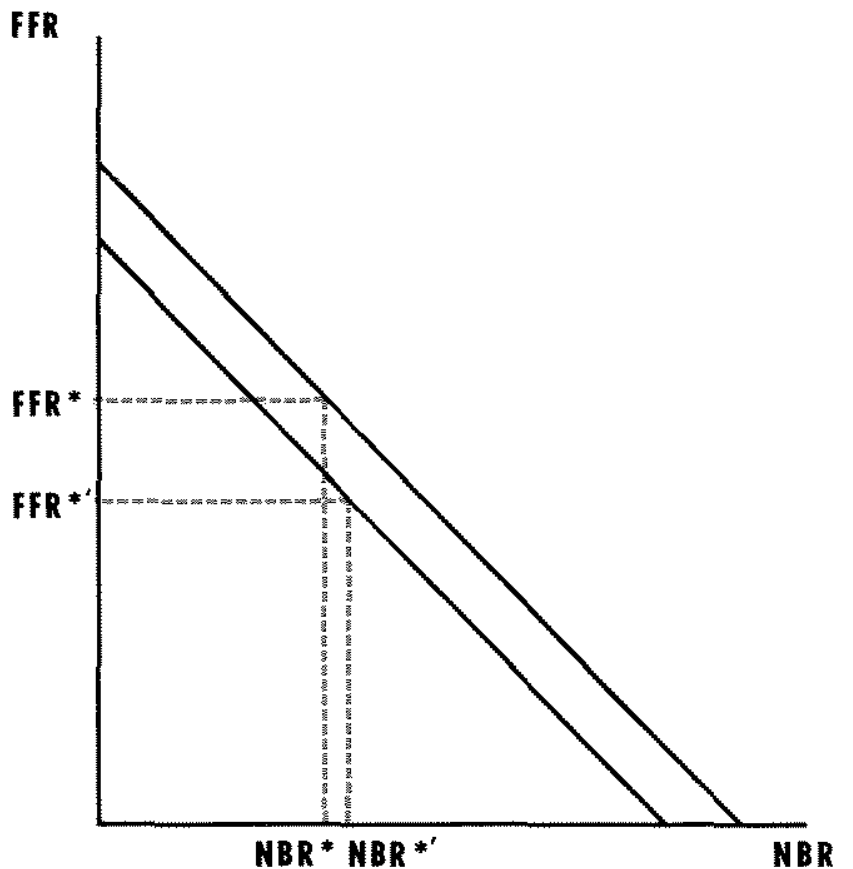

(a)

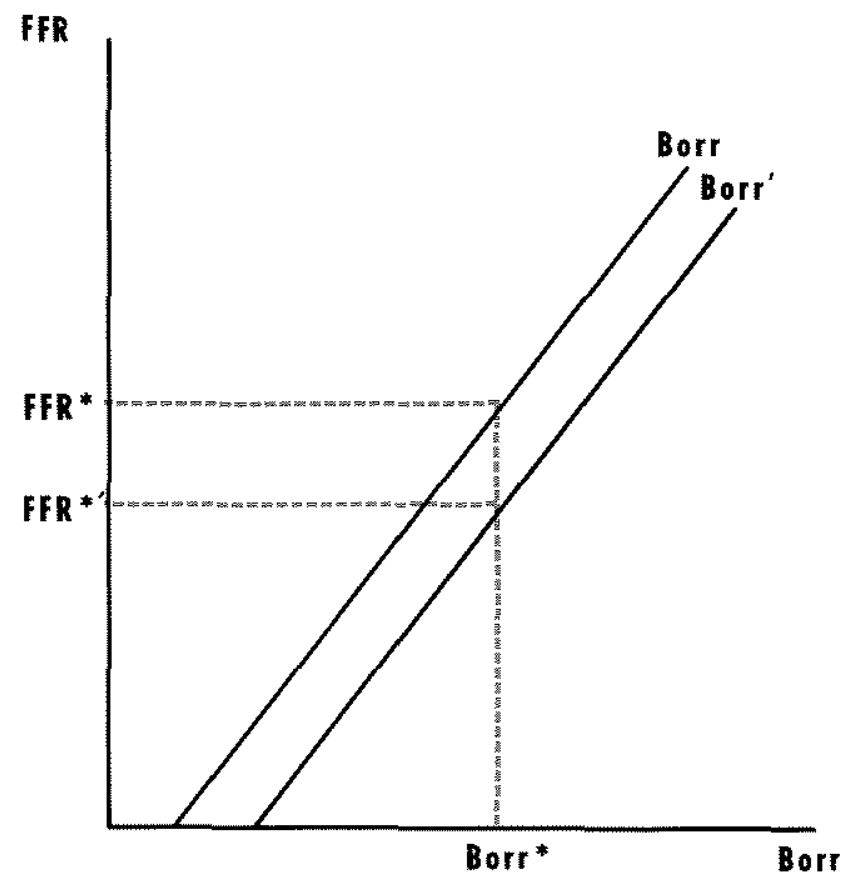

(b) 
Figure A4

The Effect of a Rise in $r$ under a Federal Rate Targeting Procedure

FFR

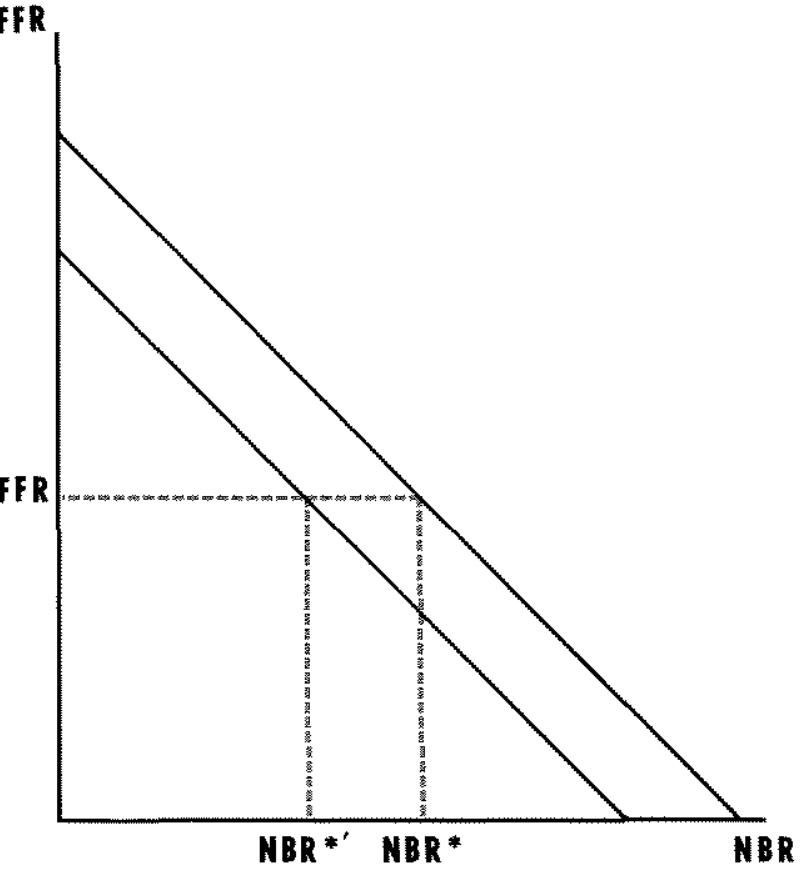

(a)

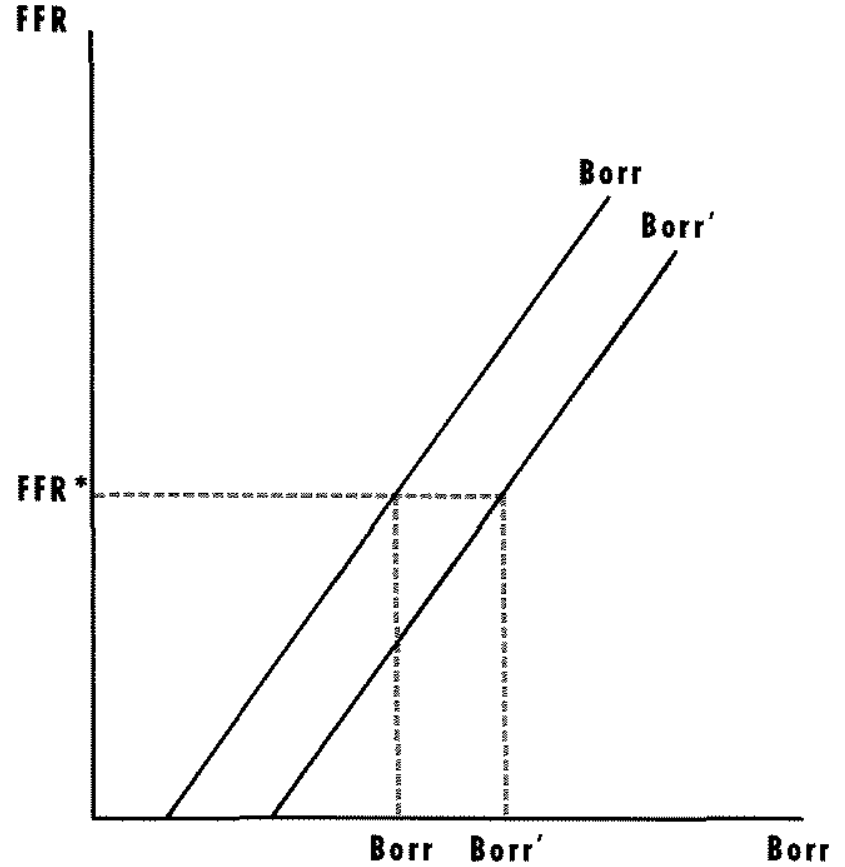

(b) ing procedure, equation $A 6$. The difference in the two procedures comes in the response to shifts in the borrowings function. In the case of an interest rate target, the Fed offsets the effect of an increase in the borrowings function by reducing nonborrowed reserves by $v$ (illustrated in figure $A 4$ ), while under a borrowings operating procedure, the fed increases nonborrowed reserves by $\left(a_{1} / b_{1}\right)$ of the shock.

Under an interest rate target, if the Fed offsets all shifts in the demand for total reserves, nether borrowings nor the funds rate will deviate from their target levels las under the borrowings procedurel. If the Fed offsets shifts in the borrowings function, the funds rate will not vary; however, there will be variability in borrowings.

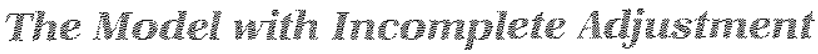

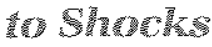

The above analysis is based on the assumption that the Fed has pexfect foresight and completely offsets shocks to total reserves or borrowings. Now assume that the Fed only offsets part of the shocks. That is, equation $A 6$ can be rewritten as

$(A 8) \mathrm{dNBH}_{1}=\delta \mathrm{u}+\delta\left(\mathbf{a}_{\mathrm{r}} / \mathbf{b}_{1}\right)$ where 8 represents the proportion of shocks which the Fed offsets over a given planning horizon, $0 \leqslant \delta \leqslant$ 1. $\delta=1$ is the complete adjustment model, $\delta=0$ represents a model in which the Fed makes no attempt to offset shocks. $\delta$ would likely increase with the length of the planning horizon.

The variance of borrowings and the funds rate under a borrowings operating procedure can be expressed as

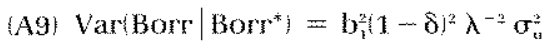

and

$$
+\left[1-b_{1} \lambda^{-4}\left(1+\delta a_{1}, b_{1}\right)^{*}\right]_{*}^{*}
$$

$(A 10) \operatorname{Var}\left(\mathbf{F F} \mathbf{B} \mid\right.$ Borr $\left.\left.^{*}\right)=(1-\delta)^{2} \lambda^{-3} \sigma_{1}^{2}+\lambda^{-2} 1+\delta a_{1} / b_{2}\right)^{2} \sigma_{v 2}^{2}$ respectively. Note that Var(Bor| Borr ${ }^{*}$ equals zero if $\delta=1$, and $\lambda^{-2}\left(b_{1}^{\prime} \sigma_{12}^{\prime}+a_{3}^{2} \sigma_{v}^{2}\right.$ if $\delta=0$. Also, $\operatorname{Var}\left(F F R \mid B O r^{*}\right)$ equals $\left(\sigma^{2} / b_{1}^{2}\right)$ if $\delta=1$, and $\lambda^{-2}\left(\sigma_{\mathrm{t}}^{2}+\sigma_{v}^{3}\right)$ if $\delta=0$.

The variance of borrowings and the funds rate under a funds rate target can be expressed as

4These expressions are obtained by applying the definition of the variance, e.g., E[Bort - E (Borr) $]^{2}$, and replacing NBR - E(NBR) with equation $A 8$. 


$$
\text { (A11) } \begin{aligned}
\operatorname{Var}\left(B o r r \mid \mathrm{FFR}^{+}\right) & =\mathbf{b}_{4}^{2}(1-\delta)^{2} \lambda^{-2} \sigma_{u 1}^{2} \\
& +\left(1-b_{1} \lambda^{-1}(1-\delta)^{2} \sigma_{v}^{2}\right.
\end{aligned}
$$

and

(A12) VarFFR $\left\{F^{*} R^{*}=\lambda^{-2}(1-\delta)^{2}\left(\sigma_{*}^{2}+\sigma_{v}^{2}\right)\right.$

respectively. "The Var Bor $\mid F^{*} R^{*}$ ) equals $\sigma_{*}^{2}$ if $\delta=1$ and

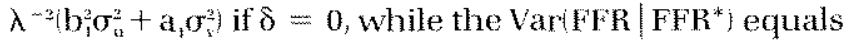
zero if $\delta=1$ and $\lambda^{-2}\left(\sigma_{u}^{2}+\sigma_{*}^{2}\right)$ if $\delta=0$.

A comparison of equations $A 9$ and $A 11$ shows that the variance of borowings will be smaller under a borrowings procedure than under an interest rate targeting procedure for $\delta>0$ and equal for $\delta=0$. The variance of the funds rate will be larger under a bor rowings procedure than under an interest rate targeting procedure for $\delta>0$ and equal for $\delta=0$.

Also, it is possible to establish conditions under which the variance of borrowings will be small relative to the variance of the federal funds rate under a borrowings target. Solving equation A10 for $(1-8)^{2}$ $\lambda^{-2} \sigma_{u}^{2}$ and substituting the result into $A 9$, yields

(A13) Var'Borr $\mid$ Bor $\left.^{*}\right)=b_{1}^{*} \operatorname{Var}\left(F_{R} R \mid\right.$ Borr $^{*} \mid$

$$
+\left[1-b_{1} \lambda^{-1}\left(1+\delta a_{k} / b_{1}\right)\right]^{3} \sigma_{v}^{2}-b_{1}^{2} \lambda^{-2}\left(1+\delta a_{1} / b_{1}{ }^{2} \sigma_{*}^{2}\right.
$$

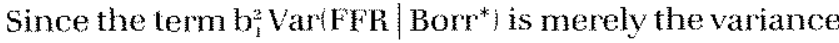
of the interest rate expressed in units comparable to VartBorr $\mid$ Borr*, after some simplification, the variance of borrowings relative to the federal funds rate under a borrowings operating procedure can be writ ten as

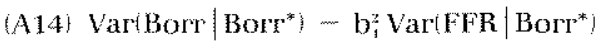

$$
=(1-\theta)^{2} \sigma_{v}^{2}-\theta^{2} \sigma_{v}^{2}
$$

where $\theta=b_{1} \lambda^{-1}\left(1+\delta a_{1} / b_{1}\right) \cdot \theta$ is a monotonic increasing function of $\delta$. The right-hand side of $A 13$ is negative if $\theta>1 / 2$. This condition will hold if $b_{1}>a_{1}$ or if $\delta \geqslant 1 / 2$. Hence, under some fairly general conditions, the variance of borrowings will be less than the variance of the federal funds rate under a borrowings operating procedure.

Likewise, equation $A 12$ can be solved for $\left.\lambda^{-2} 1-8\right]^{2} \sigma_{\mathrm{u}}^{2}$ and the result substituted into equation $A 11$. This yields

$$
\text { (A1.5) Var Bors } \begin{aligned}
\text { FHR } \left.^{*}\right) & -b_{1}^{2} \operatorname{Var}\left(F F R \mid F F R^{*}\right) \\
& =(1-\psi)^{*} \sigma_{\mathrm{v}}^{2}-\psi^{2} \sigma_{v}^{2},
\end{aligned}
$$

where $\psi=b_{1} \lambda^{-1} 1-\delta$. $\psi$ is a monotonic decreasing function of $\delta$. The right-hand side of equation $A 15$ will be negative if $\psi>1 / 2$. This will be satisfied if $b_{1}>a_{1}$ or if $\delta>1 / 2$. Consequently, if the Fed is able to offset more than half of the shocks over its planning horizon, the variance of borrowings will be larger than the variance of the funds rate under an interest rate targeting procedure.

While it may seem odd that the expressions for the relative variance do not depend on $\sigma_{x}^{3}$, this result is quite intuitive. Variation in the demand for total reserves affects the variance of borrowings only through its effect on the variation of the federal funds rate, not directly through the borrowings function. Consequently, variability in the demand for total reserves only produces variability in the market interest rate; given the borrowings function, this translates into an equal amount of appropiately scaled variability in borrowings. This result is illustrated in figure $A 5$ under the assumption that $\delta=0$.

This also explains why control errors, i.e, NBR = $\mathrm{NBR}^{*}+\omega$, where $\omega$ represents a random control error, increase the variability of both borrowings and the federal funds rate, but do not affect the variability of borrowings relative to the funds rate. This is illustrated in figure $A 5$ alternatively as $\mathrm{NBR}$ above (NBH ${ }^{2}$ ) or below ( $\left.\mathrm{NBR}^{*}\right)$ the target level $\left(\mathrm{NBR}^{*}\right)$.

\section{What}

One possibility that deserves consideration is the case where $u$ and $v$ are correlated, that is, shocks to the demand for total reserves, $u$, produce a change in the demand for borrowed reserves, $v$. To see how this affects the results, consider first the special case in which the shocks are perfectly comelated, e.g, $v=\xi u$. Assume that $\xi$ is positive, although this assumption is not citical to the results. Given these assumptions, equation $A 5$ can be rewritten as

(A16) $\mathrm{FFR}=-\lambda^{-1}\left[\mathrm{NBP}+\left(\mathrm{b}_{0}-\mathrm{a}_{\mathrm{t}}\right)-\mathrm{b}_{1} \mathrm{DA}-[1-\xi) \mathrm{u}\right]$.

Note that $(1-\xi)$ is positive if $0 \leqslant \xi<1$, zero if $\xi=1$ and negative if $\xi>1$. Given this assumption, no shifts in the borrowings function are independent of shifts in the demand for total reserves. Hence, the difference that the correlation between the error terms makes can be seen by comparing the effect of a change in $u$ under both assumptions. In the model that assumed inde. pendence, the equilibrium interest rate curve shifted to the right by u while the borrowings function did not shift, as in figure A2. Under perfect positive comelation, the market equilibrium curve shifts by $(1-\xi)$, while the borrowings function shifts by $\xi u$. These shifts determine the extent to which open market operations must be undertaken to stabilize borrowings at the target level. It also can be shown that the assump-

af $\xi<0$ and equal to $-b_{7} / a_{1}$, nonborrowed reserves will not have to change to stabilize borrowings at the target level. In this case, the leftward shift in the borrowings function just cancels the effect of the rightward shit in the equilibrium curve on nonborrowed reserves. 


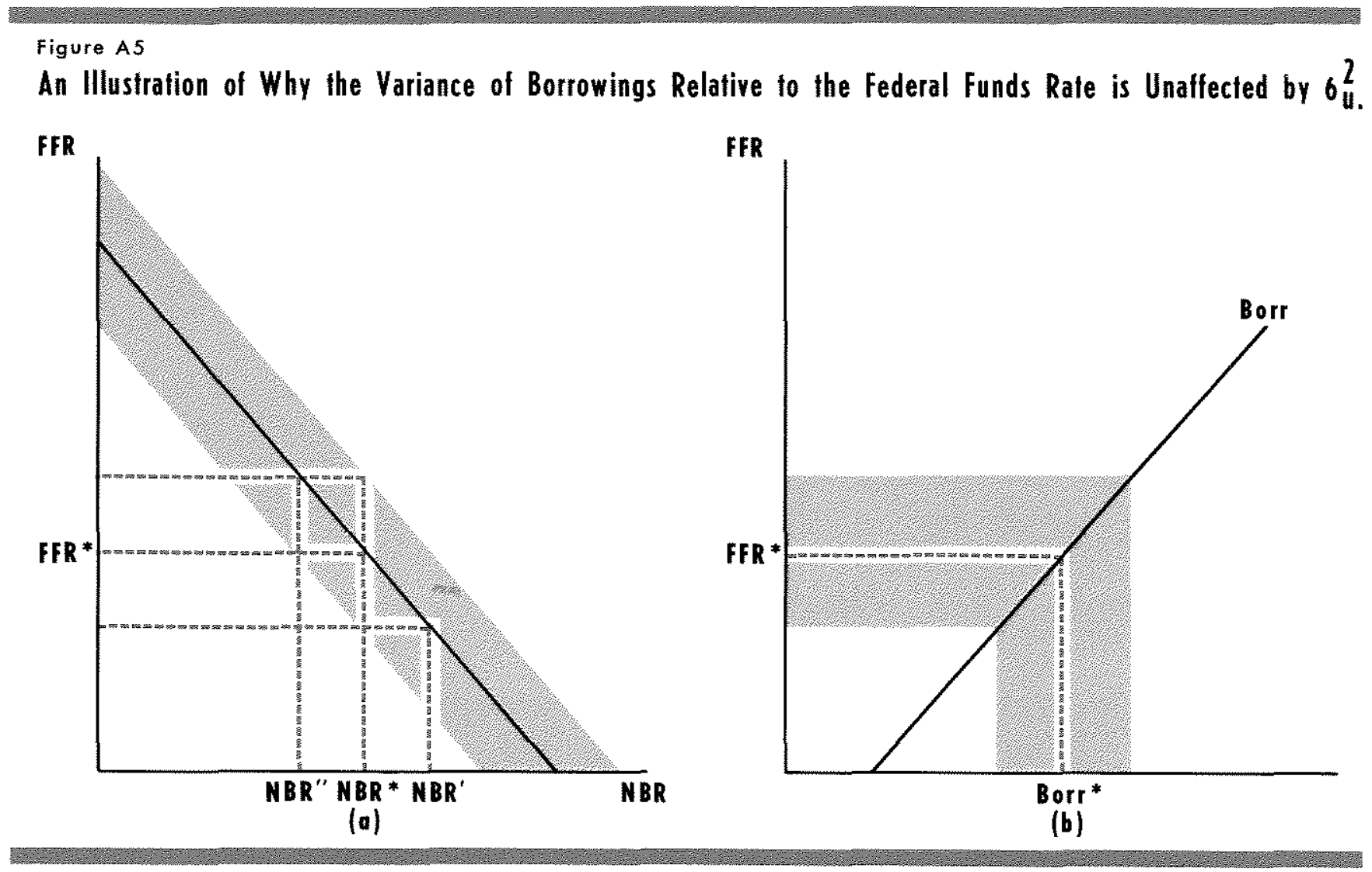

tion of perfect correlation has no effect on conchusions about the variability of borrowings andot the federal funds rate under the alternative operating procedure.

What il the stochastic disturbances are not perfectly comelated? For example, assume that $v=\xi u+\eta$, where $\eta$ is identically and independently distributed with a mean zero and a variance $\sigma_{r}^{2}$. Given this assumption, the error term of equation $A 5$ is simply $\left.-\lambda^{-1} \eta \eta+(1-\xi) u\right]$; the same as that of $A 5$ except that $u$ is replaced by $\{1-\xi$ ju and $\eta$ replaces $v$. Consequently, all of the previously stated results hold.

${ }^{6}$ The intuition for this is straightforward. The variability of borrowings under a borrowings operating procedure relative to that under a federal funds rate operating procedure depends onty on the variabil. ity of the borrowings function. Since variability of the borrowings function is the same under any of these assumptions, i.e., $v=z$ u or even $v=\xi u+n$, for both the borrowings and federal funds rate targets, the assumption made does not affect the general conclusion about the variability under these procedures. This is also the reason the general conclusions about the variance of borrowings relative to the federal funds rate under the borrowings operating procedure are unaffected by this assumption. 


\section{Appendix B \\ A More Detailed Analysis of the Effect of a Change in the Borrowings Assumption on the Federal Funds Rate}

The purpose of this appendix is to present detailed results on the effect of a change in the borrowings assumption on the federal funds rate. One way to calibrate such effects is to estimate a reduced form equation for the level of the federal funds rate (FFR):

(B1) $\mathrm{FFR}_{4}=\alpha+\beta \mathrm{DR}_{t}+\mu \mathrm{BA} A_{t}+\varepsilon_{\mathrm{s}}$

where DR and $B A$ denote the level of the discount rate and borrowings assumption. Under a strict borrowedreserves operating procedure, $\beta$ should be positive and equal one. OLS estimates of equation $B 1$ are reported in the top half of table B1 for the LHP and CRR periods. Three significant aspects of these results deserve particulat attention. First, the hypothesis that $\beta$ $=1$ is rejected at the 5 percent level during both periods. Second, the $\mathrm{Q}$ statistic does not indicate loworder serial correlation during the LRR period, but does indicate it during the CRR period. Nevertheless, the residuals show a pronounced quarterly seasonal spike during the LRP period clearly evident from chart 2 of the text. Thit, the standard error of the equation increases dramatically during the CRR period, indicating increased variability of the FFR under CRR. (This is tue whether weekly or reserve period data are used.
Because of the seasonal spike during the LRR period and serial correlation of the residuals during the CRR period, the equations were reestimated including lagged dependent variables. The results are reported on the bottom half of table BI. (Four lags of FFH are included during the CRR period; in addition, $\mathrm{FFR}_{1-13}$ is included during the LRR period.) During the LRR period, the coefficient on BA increased somewhat, although its t-ratio declined. Also, the estimate of $\beta$ declined substantially and the hypothesis that $\beta=1$ is rejected at very low significance levels. For the CRR period, the estimated coefficient on BA declined by nearly two-thirds and the t-ratio declined dramatically.

There are several reasons for questioning the estimates from the level equations. 'The first reason relates to the time-series properties of the individual series themselves. $\mathrm{BA}$ is highly autocorrelated, as table $\mathrm{B}$ 2 indicates. The fact that the levels of BA and FFR are highly autocorrelated affects the relationship between them. This is evident in the simple correlation coefficients given in table B3. The simple correlation of FrR and $B A$ is higher than that of FFR and actual adjustment plus seasonal borrowing, Borr, during the LRR period; however, the correlation coefficient of first

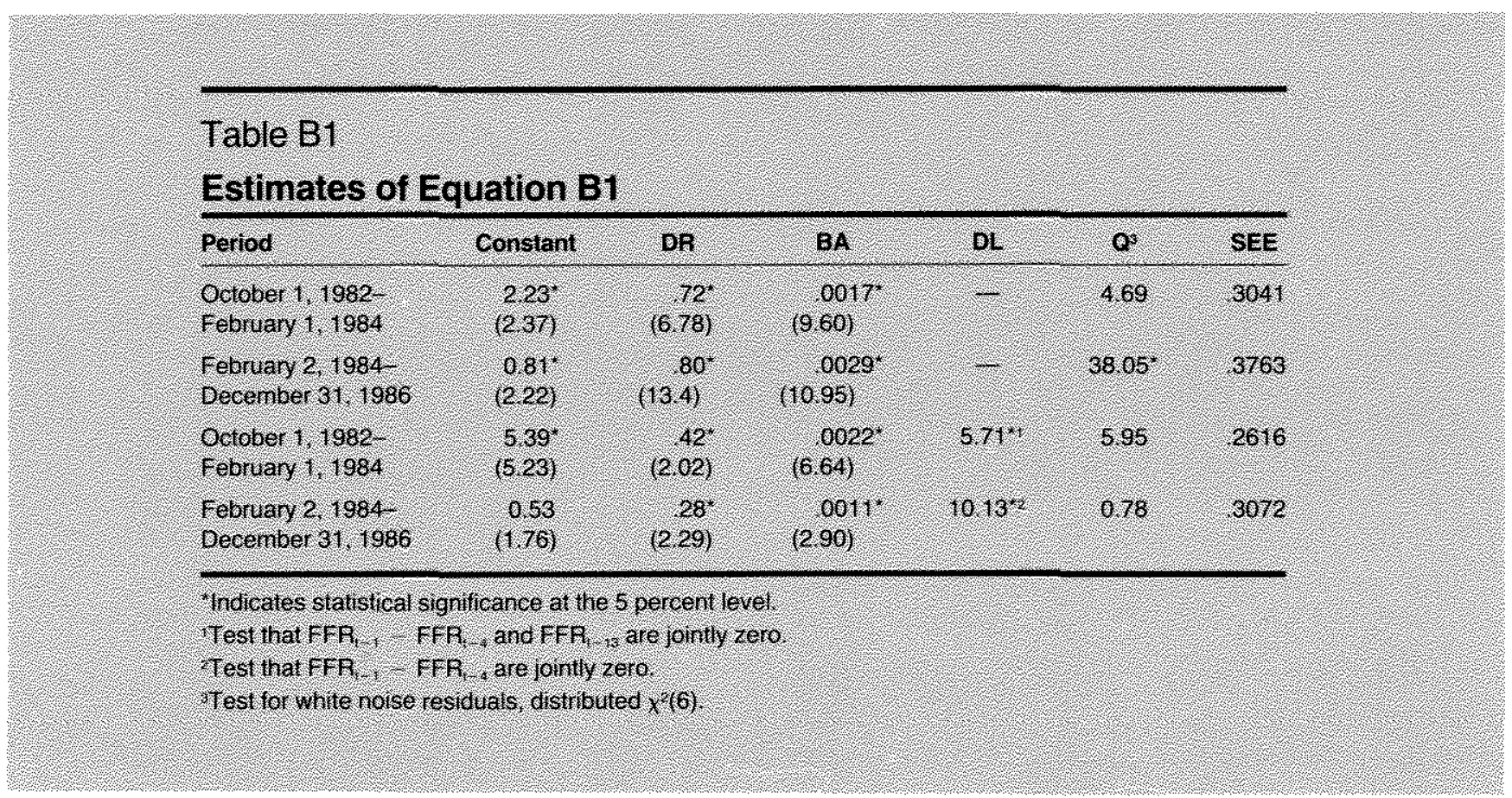


Table B2

Autocorrelations of Time-Series Variables for Reserve-Period Data

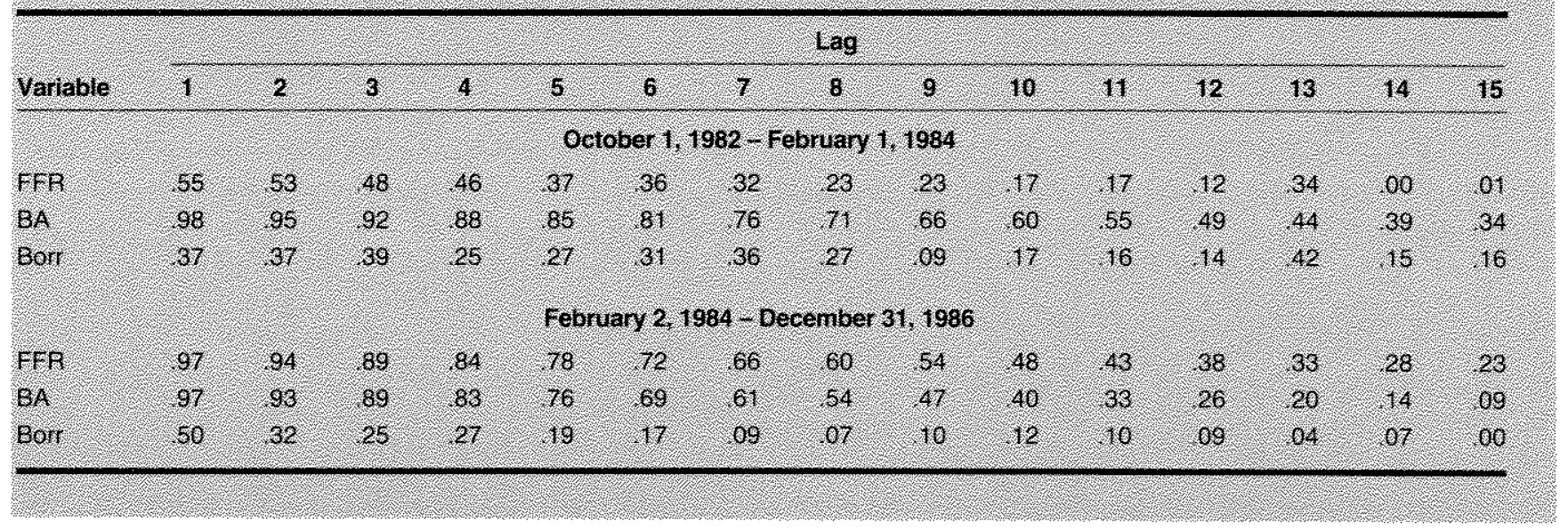

\section{Table B3}

\section{Simple Correlations of Time-Series Variables for Reserve-Period Data}

\begin{tabular}{|c|c|c|c|c|}
\hline Varables & 84 & Bory & 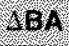 & 180 \\
\hline & \multicolumn{4}{|c|}{ Cerober l 19882 -rebruary 1,1984} \\
\hline \multirow{3}{*}{ 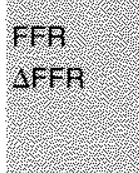 } & 606 & 540 & 2 & 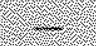 \\
\hline & & & 166 & 563 \\
\hline & \multicolumn{4}{|c|}{ February 2,1984 - December 31,1986} \\
\hline min & 903 & 492 & 3 & 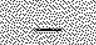 \\
\hline 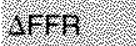 & & r. & 78 & .024 \\
\hline
\end{tabular}

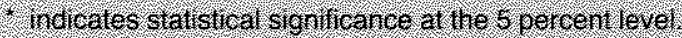

differences of FFR and $\mathrm{BA}$ is dramatically different from that of their levels. This is not ture, however, of the correlation between Borr and FFR and $\Delta$ Borr and $\triangle F F R$. For the CRR period, when their autocorrelations match closely, the correlation between FFR and $B A$ is high. Yet in first-difference form, the correlation is essentially the same as during the LRR period and is not statistically significant.

A second reason to be cautious of the level equation results has to do with the long-run stability of the borrowings function itself. The borrowings assumption does not represent an exogenous supply of borrowings; more precisely, it is an exogenous target level that the Fed attempts to induce depository institutions to hold by altering the supply of nonborrowed reserves. Consequently, actual borrowings can, and do, deviate from the desired level. Nevertheless, over a longer time period, the average level of borrowings can be close to the desired level. This is especiatly likely if adjustments are made to nonborrowed reserves or if the borrowings assumption itself is changed to keep it in line with actual borrowings levels.

Therefore, when the level of the funds rate is regressed on the level of the borrowings assumption. there is a tendency to retrieve this long-run relationship to a greater or smaller degree, depending on how closely the borrowings assumption mimics actual borrowings.'

In order to more closely capture the effect of an exogenous change in the borrowings assumption on the funds rate, first differences of the funds rate are regressed on first differences of the borrowings assumption. This should yield consistent estimates of the immediate response of the federal funds rate to an exogenous change in the borrowings assumption, even if the level specification is correct. ${ }^{2}$ Moreover, it

Augmented Dickey-Futler tests for stationarity applied to borrowings and the funds rate indicate that both series are integrated of order one, i.e. I(1) for the LRR period. When the lest is applied to the residuals from OLS estimates of equation 1 , however, the results indicate that borrowings and the funds rate are cointegrated in the Engle-Granger (1987) sense. The augmented Dickey-Fuller test indicates that $\mathrm{BA}$ and $\mathrm{FFR}$ are $(2)$ over the CRR period. Yet the test indicates that the residuals from equation 1 estimated over this period are stationary.

The OLS estimate of $b_{1}$, of equation 1 from the text for the LRR period is 471 . This yields an implied coefficient estimate of $\beta$ of equation $B 1$ equal to $.0021(1 / 471)$. The implied estimate of $\beta$ for the CRR period using reserve-period data is .0038 (1/260).

¿See Plosser, Schwert and White (1982). 


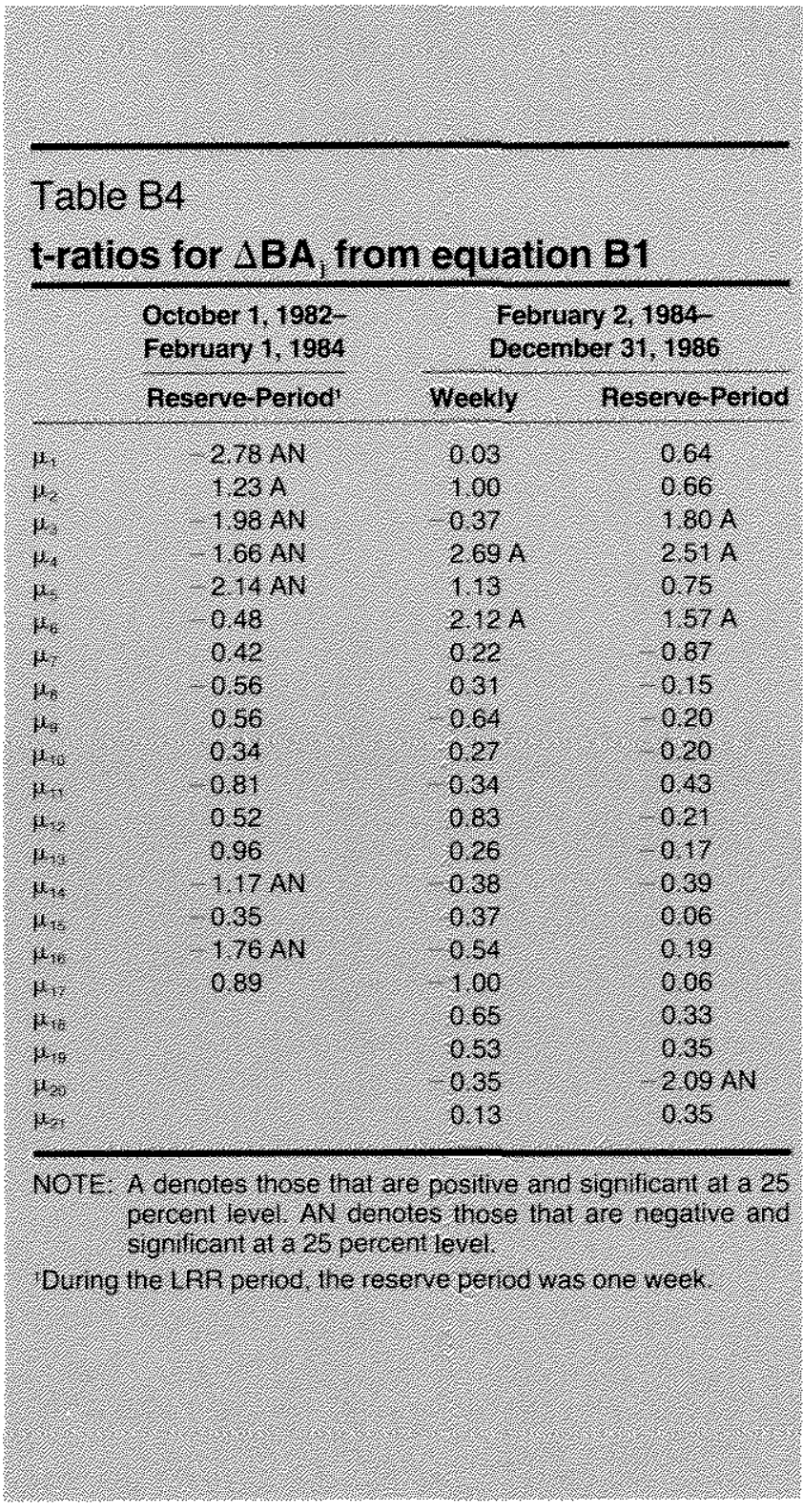

should avoid spurious correlation often experienced when the levels of nonstationary series are used.

Finally, because the borrowings assumption is changed infrequently, changes in the borrowings assumption can be partioned into those that do have a significant effect on the federal funds rate and those that do not. This is done by estimating the equation:

$$
\begin{aligned}
& \text { K } \\
& \text { (B2) } \Delta F R_{t}=\alpha_{t}+\underset{i=1}{2} \alpha_{i} \Delta \mathrm{FFR}_{\mathrm{t}-\mathrm{i}}+\beta_{\mathrm{a}} \Delta \mathrm{OPRT}_{\mathrm{i}}+\beta_{1} \Delta \mathrm{DRNT} \\
& \text { 1. } \\
& +\sum_{j=1} \mu_{j} \Delta B A_{i, k}+\varepsilon_{t}
\end{aligned}
$$

where $\triangle B A_{1, i}$ takes on the value of the jth change in the borrowings assumption during the period and is zero otherwise. $L$ denotes the number of changes in the

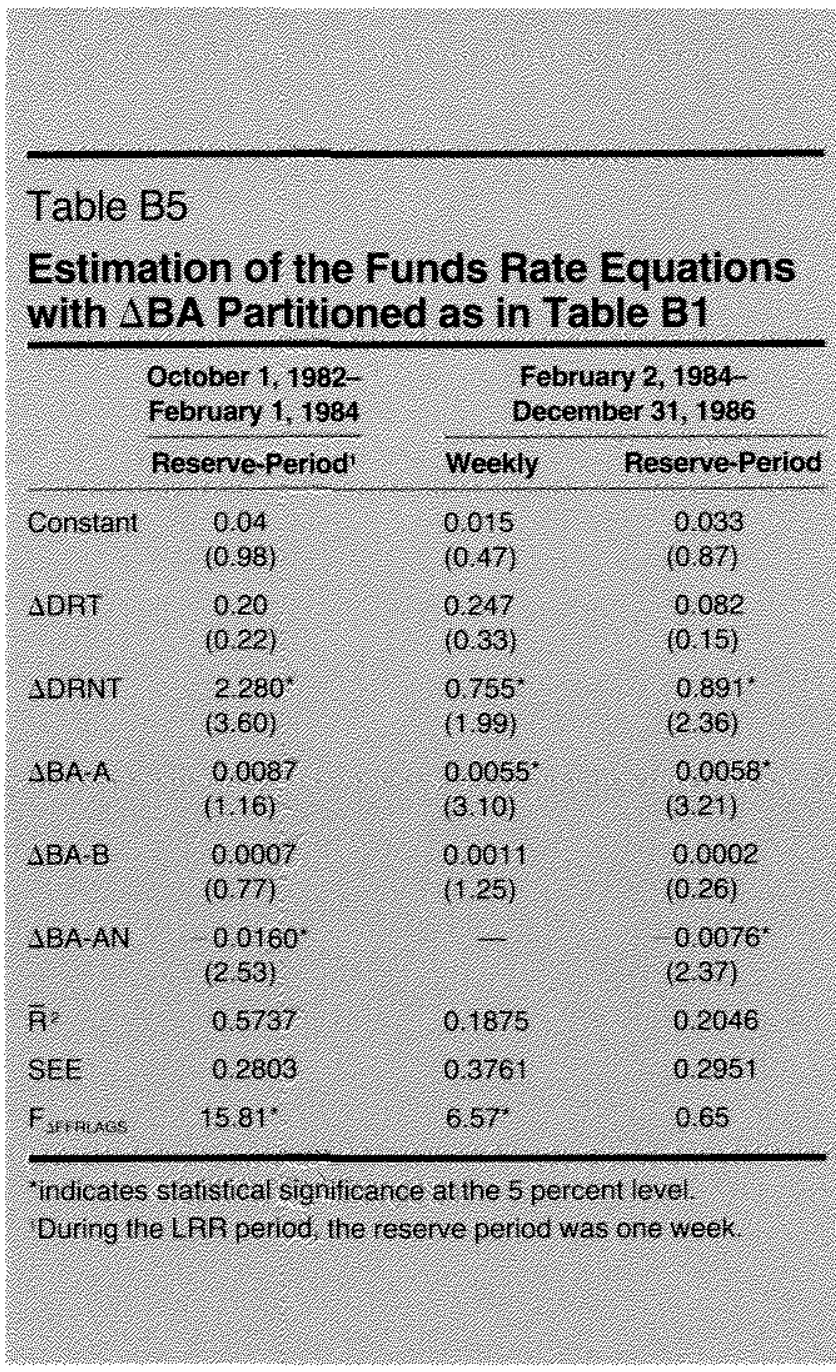

borrowings assumption over the sample period. The estimated standard error from this equation, $\alpha_{*}^{*}$, meam sures the conditional variance of $\triangle F F R$ for periods when $\triangle B A=0$. Hence, the tratio for the ith $\triangle B A$ indicates how much the federal funds rate moved during this period relative to periods when the borrowings assumption was unchanged.

The tratios for each $\triangle B A$ are reported in table $B 4$. The results indicate that, of the 17 changes in the borrowings assumption during the LRP period, 10 were inversely related to changes in the federal funds ate. During the CRR period, either seven or eight of the 21. $\triangle B$ As were inversely related to the funds rate, depending on whether weekly or reserve-period data are used. The results in table $B 4$ can be used to partition $\triangle B A$ into those that have a positive signifi-

\footnotetext{
I I daily data were used, $L$ is equal to the number of changes on the borrowings assumption over the sample period. When weekly or reserve-period data are used, the data are averaged on a pro-rata basis. Consequently, $L$ denotes the number of weeks of reserve periods that are affected. This is usually larger than the number of changes in the borrowings assumption itself.
} 
cant effect on the funds rate, $\triangle B A-A$, those that have a significant negative effect, $\triangle B A-A N$, and all others, $\triangle B A-B$. This was done by including in the $A$ ot $A N$ groups all $\triangle B A$ s that are significant at the 0.25 percent level using standand analysis. Those changes in $\mathrm{BA}$ that are in the $A$ or $A N$ groups are designated correspondingly in table B4.

Estimates of the same basic equation with the partitioned data are presented in table 35 . In all cases, except the single observation in the $A$ group during the LRR period, the coefficients on the $A$ and $A N$ partitions are significant at the 5 percent level. More importantly, the coefficients on the changes in the borrowings assumption in the $B$ partition. which account for the vast majority of changes in the borrow ings assumption, were uniformly insignifeant at the 5 percent level. This evidence indicates that the link between changes in the borrowings assumption and the federal funds rate is, at best, weak. 